\title{
Microstructural, Mechanical, and Electrochemical Analysis of Duplex and Superduplex Stainless Steels Welded with the Autogenous TIG Process Using Different Heat Input
}

\author{
Gláucio Soares da Fonseca ${ }^{1, *}$, Luis Otavio Rodrigues Barbosa ${ }^{1}$, Elivelton Alves Ferreira ${ }^{1}$, \\ Carlos Roberto Xavier ${ }^{2}$ and José Adilson de Castro ${ }^{1}$ \\ 1 Graduate Program on Metallurgical Engineering, Federal Fluminense University, \\ Avenida dos Trabalhadores, 420, Vila Santa Cecília, 27255-125 Volta Redonda, Rio de Janeiro, Brazil; \\ luisbarbosa@id.uff.br (L.O.R.B.); eliveltonalves@id.uff.br (E.A.F.); joseadilsoncastro@id.uff.br (J.A.d.C.) \\ 2 Mechanical Engineer Department-UniFOA, Avenida. Paulo Erlei. Alves. Abrantes, 1325, Três Poços, \\ 27240-560 Volta Redonda, Rio de Janeiro, Brazil; xavier@metal.eeimvr.uff.br \\ * Correspondence: glaucio@metal.eeimvr.uff.br; Tel.: +55-24-2107-3728
}

Received: 1 November 2017; Accepted: 27 November 2017; Published: 1 December 2017

\begin{abstract}
Duplex Stainless Steels (DSS) and Superduplex Stainless Steels (SDSS) have a strong appeal in the petrochemical industry. These steels have excellent properties, such as corrosion resistance and good toughness besides good weldability. Welding techniques take into account the loss of alloying elements during the process, so this loss is usually compensated by the addition of a filler metal rich in alloying elements. A possible problem would be during the welding of these materials in adverse conditions in service, where the operator could have difficulties in welding with the filler metal. Therefore, in this work, two DSS and one SDSS were welded, by autogenous Tungsten Inert Gas (TIG), i.e., without addition of a filler metal, by three different heat inputs. After welding, microstructural, mechanical, and electrochemical analysis was performed. The microstructures were characterized for each welding condition, with the aid of optical microscopy (OM). Vickers hardness, Charpy-V, and cyclic polarization tests were also performed. After the electrochemical tests, the samples were analyzed by scanning electron microscopy (SEM). The SDSS welded with high heat input kept the balance of the austenite and ferrite, and toughness above the limit value. The hardness values remain constant in the weld regions and SDSS is the most resistant to corrosion.
\end{abstract}

Keywords: duplex stainless steel; superduplex stainless steel; heat input; autogenously TIG

\section{Introduction}

Duplex Stainless Steels (DSS) and Superduplex Stainless Steels (SDSS) are widely used in many industrial sectors, but also have a strong appeal in the petrochemical industry. Applied to oil extraction structures, pipes, and pressure vessels, these steels combine good mechanical properties with an excellent ability to withstand the corrosive media to which they are exposed. These characteristics are directly linked to the biphasic structure formed, composed basically of ferrite and austenite in approximately equal proportions [1-14]. For the application of these steels, welding processes are usually involved, and weldability is another positive point, as DSS and SDSS are weldable by almost all processes available in the market. Most of the processes employed for the welding of this material take into account the modification of both the microstructure and chemical composition in the weld region [5]. In order not to compromise the properties of the material, almost all the welding processes count on the addition of filler metal in the welded joint. The filler metals are manufactured to compensate possible losses of alloying elements during welding of base metal (BM), and their chemical 
composition is always similar to the base metal to be welded [5]. Although the literature considers the use of filler metal as indispensable, some studies have been carried out without the addition of filler metal [6]. In practice, in some situations in the field where the repair in steel is necessary, the professional can have only the option of autogenously welding. Another point of emphasis in studies of these steels is the heat input applied [7]. Reference values for this heat input are around 0.5-3.0 KJ/mm. Values close to the former considered a low input and values close to the latter a high input. Recently, Mohammed GR and co-authors [7] published a review on the effects of heat input on microstructure, mechanical properties, and corrosion in duplex stainless steels. An important conclusion is that low heat input in the welding should be avoided, since it would mean a rapid cooling rate and therefore would not have sufficient austenite in the weld metal (WM) and the heat affected zone (HAZ), and would lose the balance of austenite and ferrite, which is characteristic of DSS. In this case, it can generate precipitation of the intermetallic, $\mathrm{Cr}_{2} \mathrm{~N}$, since $\mathrm{N}$ is poorly soluble in ferrite at low temperature. This leads to the worsening of pitting corrosion resistance. This is explained by the depletion of the chromium in the ferrite near the precipitates of $\mathrm{Cr}_{2} \mathrm{~N}$. However, a high heat input means a slow cooling rate, which consequently favors the formation of austenite, both in the WM and in the HAZ, thus obtaining a more balanced microstructure (ferrite-austenite), but still being able to precipitate $\mathrm{Cr}_{2} \mathrm{~N}$. In addition to $\mathrm{Cr}_{2} \mathrm{~N}$, in these steels, depending on the heat treatment or welding process performed, intermetallic phases, such as sigma, Chi, among others may arise. These phases are also undesirable, since their nucleation and growth are detrimental to the mechanical properties and corrosion resistance. Numerous articles on the subject can be found in the literature [1-4,8-14]. Mohammed GR and co-authors [7] also concluded that the analysis of the effects of heat input on different types of duplex stainless steels welded by different techniques still needs further studies for a deeper understanding on the subject. In order to enhance this discussion, duplex (SAF 2205 and SAF 2304) and superduplex (SAF 2507) stainless steels were welded by the autogenous Tungsten Inert Gas (TIG) or Gas tungsten arc welding (GTAW) process with three different heat inputs. These heat input values were used based on the literature [7]. After welding, microstructural, mechanical and electrochemical analyses were performed, and it was possible to build the positive and negative points for each steel, thus enriching the knowledge about the autogenous TIG process, which is of high industrial interest.

\section{Materials and Methods}

\subsection{Materials}

Three commercial hot rolled duplex stainless steels were studied. Pieces were cut from the received plates in order to obtain samples with dimensions of $8 \mathrm{~mm} \times 60 \mathrm{~mm} \times 210 \mathrm{~mm}$. The steels are:

Duplex Stainless Steel UNS S31803, designated in this work as SAF 2205;

Lean Duplex Stainless Steel UNS S32304, designated in this work as SAF 2304;

Superduplex Stainless Steel UNS S32750, designated in this work as SAF 2507.

The chemical compositions are given in Table 1:

Table 1. Chemical Composition of Duplex Stainless Steel (DSS) and Superduplex Stainless Steel (SDSS) (wt \%).

\begin{tabular}{ccccccccccc}
\hline SAF & C & Si & Mn & P & S & Cr & Ni & Mo & N & Cu \\
\hline 2205 & 0.023 & 0.320 & 1.85 & 0.030 & 0.001 & 22.50 & 5.30 & 2.90 & 0.166 & 0.030 \\
2304 & 0.016 & 0.410 & 1.49 & 0.025 & 0.0001 & 22.62 & 3.58 & 0.24 & 0.112 & 0.450 \\
2507 & 0.020 & 0.328 & 0.85 & 0.027 & 0.0009 & 24.89 & 6.82 & 3.72 & 0.278 & 0.156 \\
\hline
\end{tabular}




\subsection{Methods}

The following procedures were performed: welding of the material through the autogenous TIG process, using three different heat inputs. After welding, the microstructural characterization of base metal (BM), low temperature heat affected zone (LT-HAZ), high temperature heat affected zone (HT-HAZ), and weld metal (WM) were obtained, besides quantifications of the present phases of each weld region. For analysis of mechanical properties, two tests were performed. The first one: Vickers hardness test, obtaining a hardness profile of the regions; and the second: Charpy-V impact test conducted at critical temperature of $-46^{\circ} \mathrm{C}$ with sub-sized specimens. Finally, to obtain information on the corrosive behavior of steels, the electrochemical test by the potentiodynamic polarization method of the base metal and weld region was performed.

\subsubsection{Welding}

The welding equipment used was the MigPulse 4001 DP from Eutectic Castolin, the welding torch being coupled to a mobile car with its speed controlled by a frequency inverter. The welding of all the plates was carried out in a single pass and without deposition of filler metal. The protection of the weld pool was made using a shielding gas of pure argon at the flow rate of $15 \mathrm{~L} / \mathrm{min}$. The electrode used was a $1 / 8^{\prime \prime}$ diameter tungsten and thorium alloy (red tip). Table 2 shows the heat input calculated with the aid of Equation (1) [7], and the parameters obtained during the welding of the plates

$$
H=\frac{\eta E I}{V}
$$

where $\eta=$ Efficiency of heat transfer. In this case $\eta=0.80$ [15]; $E=$ Volts; $I=$ Amperes; and $V=$ Velocity of the welding heat source $(\mathrm{mm} / \mathrm{s})$. The experimental parameters presented in Table 2 were selected using pre-welding trials to attain extreme conditions at the lowest and highest heat inputs. The conditions selected were those that offer suitable welding aspects at these extreme heat inputs in order to explore the parameters beyond the literature recommendations.

Pieces were cut from the plates according to the schematic drawing shown in Figure 1. The beginning and the end of the weld were discarded, since they are regions with heat input variation related to the arc stabilization.

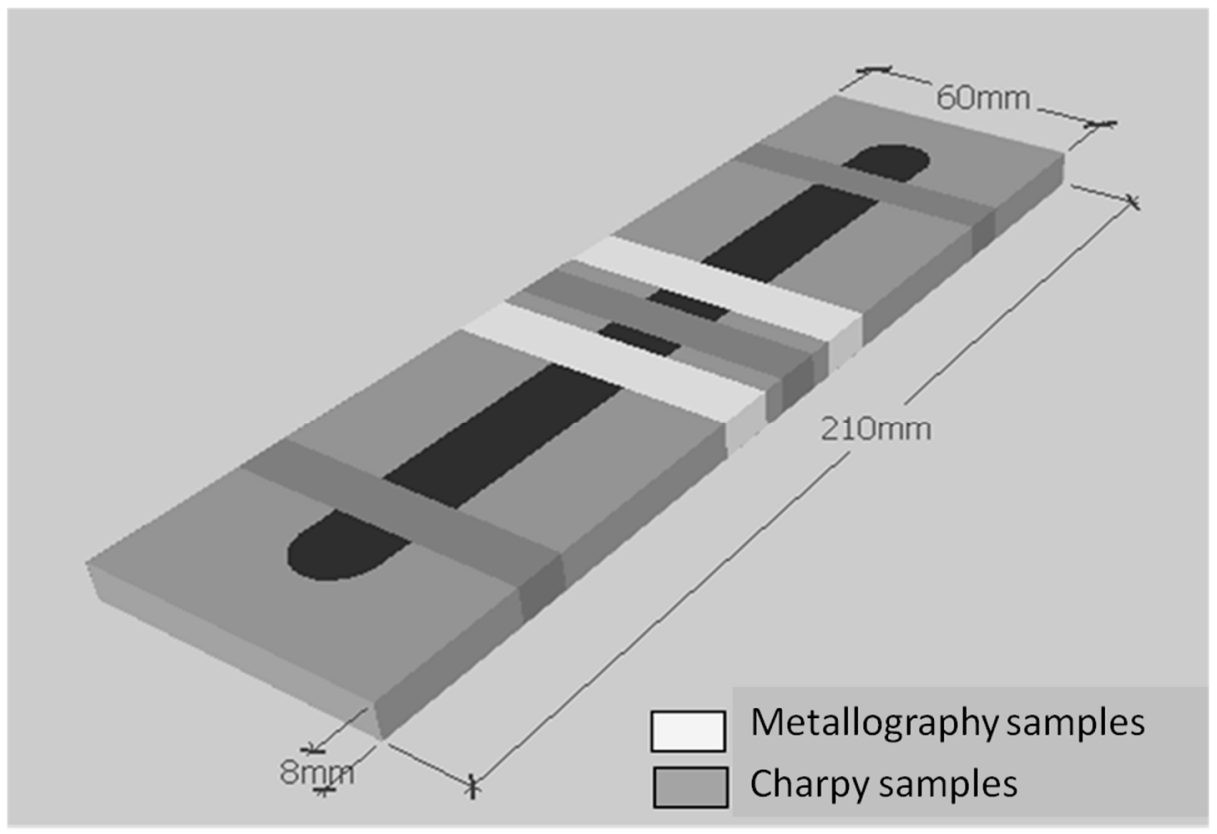

Figure 1. Schematic drawing showing sample cuts. 
The specimens were ground with emery paper down to 2500 mesh. The samples were metallographic polished with $1 \mu \mathrm{m}$ and $0.05 \mu \mathrm{m}$ alumina solution. After polishing, the samples were etched by Beraha reagent, composed of $20 \mathrm{~mL}$ hydrochloric acid $(\mathrm{HCl}), 80 \mathrm{~mL}$ distilled water, and $0.3 \mathrm{~g}$ potassium metabissulfide $\left(\mathrm{K}_{2} \mathrm{~S}_{2} \mathrm{O}_{5}\right)$ for $100 \mathrm{~mL}$ of aqueous solution. With this etching for $1 \mathrm{~min}$, ferrite, austenite, and sigma phase, if it is present, can be distinguished. This procedure was presented in [1].

Table 2. Parameters obtained by the Tungsten Inert Gas (TIG) welding process.

\begin{tabular}{ccccc}
\hline SAF & $\boldsymbol{I}(\mathbf{A})$ & $\boldsymbol{E}(\mathbf{V})$ & Arc $(\mathbf{m m})$ & Heat Input $(\mathbf{k J} / \mathbf{m m})$ \\
\hline 2205 & 76 & 9 & 2 & 0.5 \\
2304 & 76 & 9 & 2 & 0.5 \\
2507 & 76 & 9 & 2 & 0.5 \\
2205 & 211 & 13 & 2 & 2.2 \\
2304 & 211 & 15 & 2 & 2.5 \\
2507 & 211 & 14 & 2 & 2.4 \\
2205 & 232 & 15 & 2.5 & 2.8 \\
2304 & 285 & 15 & 2 & 3.4 \\
2507 & 249 & 16 & 2.5 & 3.2 \\
\hline
\end{tabular}

Note: $I$ is amperage, $E$ is voltage, and Arc is the arc length. The heat source velocity $(V)$ was maintained at $1 \mathrm{~mm} / \mathrm{s}$ and the electrode tip angle at $30^{\circ} \mathrm{C}$ for all welded steels.

\subsubsection{Temperature Evolution and Cooling Rates}

The temperature evolutions and heating and cooling rates during the welding procedure are important variables to predict the phase balance and deleterious precipitates. In order to monitor and estimate these variables during welding procedures, accurate mathematical models are important allies. We used a previously developed mathematical model to discuss the transient temperature distributions and cooling rates, and hence the precipitates formation [15-17]. The model is based on the transient heat equation with moving double ellipsoid heat source accounting for the heat input and velocities of the torch. Equations (2)-(4) show the fundamentals of the model equations.

$$
\begin{gathered}
\frac{\partial}{\partial t}\left(\rho c_{p} T\right)+\operatorname{div}\left[\rho c_{p}(\vec{U}) T\right]=\operatorname{div}[k(\operatorname{grad}(T))]+S \\
q_{r}(x(t), y(t), z(t))=\frac{6 \sqrt{3} f_{r}\left(Q_{t}\right)}{a b_{r} c \pi \sqrt{\pi}} \operatorname{EXP}\left(-3\left(\frac{x(t)}{a}\right)^{2}\right) \operatorname{EXP}\left(-3\left(\frac{y(t)}{b_{r}}\right)^{2}\right) \operatorname{EXP}\left(-3\left(\frac{z(t)}{c}\right)^{2}\right) \\
q_{f}(x(t), y(t), z(t))=\frac{6 \sqrt{3} f_{r}\left(Q_{t}\right)}{a b_{f} c \pi \sqrt{\pi}} \operatorname{EXP}\left(-3\left(\frac{x(t)}{a}\right)^{2}\right) \operatorname{EXP}\left(-3\left(\frac{y(t)}{b_{f}}\right)^{2}\right) \operatorname{EXP}\left(-3\left(\frac{z(t)}{c}\right)^{2}\right)
\end{gathered}
$$

Equations (3) and (4) are used to impose the volumetric heat source, $S$, in the Equation (2) due to the moving arc. The heat source is specified depending on the position and time accounting for the moving welding torch. The position coordinates, $x(t), y(t)$, and $z(t)$, are referenced to the moving coordinate system located at the torch center of the welding system. The velocity field $U$, appearing in Equation (2), represents the welding velocity and assumed constant throughout the calculation, given by the experimental data. The total heat input, $Q_{t}=\eta E I$, are given by Equation (1) using measured data of the current, $I$, and voltage, E. The materials properties appearing in Equation (2), $\rho, C_{p}$, and $k$, are temperature- and composition-dependent for each material and stand for the material density $\left(\mathrm{kg} / \mathrm{m}^{3}\right)$, heat capacity $(\mathrm{kJ} / \mathrm{kg} \cdot \mathrm{K})$, and thermal conductivity $(\mathrm{kW} / \mathrm{m} \cdot \mathrm{K})$, respectively. The initial and boundary conditions for Equation (2) are considered as given initial temperature distribution and imposed natural convection and radiation boundary conditions, respectively. The spatial heat source distribution parameters $f_{f}$ and $f_{r}$ are the fraction of the total heat received in the front and rear quadrant used in Equations (3) and (4), respectively. The parameters are chosen attaining the relationship, 
$f_{f}+f_{r}=2$. The heat input constant parameters, $a, b_{f}, c$, and $b_{r}$, are selected to account for the torch heat distribution. These constant parameters were assumed based on previous work [15-17]. The factors $f_{f}$ and $f_{r}$ were assumed as 0.6 and 1.4 respectively, while $\eta$, efficiency of heat transfer was assumed 0.80 for the calculations.

\subsubsection{Volume Fraction, Vickers Hardness, Charpy Test}

The samples were examined with Nikon Eclipse LV150 Optical Microscope (Nikon, Tokyo, Japan). Micrographs were analyzed by public domain software image J. Volume fractions $\left(V_{V}\right)$ of ferrite and austenite were carried out by conventional quantitative metallography techniques [18]. That is, it was applied to the classic stereological equation $V_{V}=A_{A}$, where the volumetric fraction is equal to the area fraction $\left(A_{A}\right)$ occupied by the phase in the micrograph. This procedure was performed for all weld regions. Ten micrographs were obtained in each weld region (LT-HAZ, HT-HAZ, WM) and four micrographs in the BM. In order to determine the hardness of the samples, the tests were performed in WPM LEIPZIG HPO 250 Vickers Hardness Tester. The experiments were carried out with a load of $10 \mathrm{~kg}$-Force by $20 \mathrm{~s}$. A hardness profile was obtained through all regions. The Charpy test was performed following the ASTM E23-16b [19] and Norsok-M 601 [20] standards. The ASTM standard was used as a specification of the size of the specimens, because, taking into account the dimensions of the plates, it was necessary to make specimens named sub-sized as they were smaller than the standard samples. Thus, the specimens had the following dimensions: $10 \mathrm{~mm} \times 5 \mathrm{~mm} \times 55 \mathrm{~mm}$; the V-notch was made in weld central region with $1 \mathrm{~mm}$ of depth. With this weld penetration depth in the steel, it was not possible to perform the test for the plates that were welded using the heat input lowest values, since the depth was not enough for the making of the notch to be entirely within the weld metal. Therefore, Charpy tests were performed only with the plates that were welded with medium and high heat input. From the welded plates, three specimens were prepared for each steel, as shown schematically in Figure 1, following the criterion of preparing one at the beginning, another from the middle, and one at the end of the weld. Thus, a total of 18 specimens were produced. The samples were machined with the Romi D1250 Machining Center. In order to test the material in adverse situations, which simulate its application in extreme cases, the test was performed at $-46^{\circ} \mathrm{C}$, which is indicated, according to Norsok [20], as the critical temperature for stainless steels. For the procedure, all the specimens were placed inside a thermal insulation chamber together with the metal clamp to later manipulate them. To reach the specified temperature, liquid nitrogen was used. The samples remained inside another 10 minutes after the thermal chamber reached $-46^{\circ} \mathrm{C}$. The tests were run in sequence, using the Wolpert $300 \mathrm{~J}$ impact machine.

\subsubsection{Electrochemical Tests, Scanning Electron Microscopy (SEM)}

With the aid of Emstat3 potentiostat together with the PSTrace software (PalmSensr, EmStat3+, Houten, Utrecht, The Netherlands), the samples were subjected to the cyclic polarization test. The procedure was performed according to that shown in [21]. A sample of each steel for each heat input used was tested on both the base metal and the weld region. The tests were conducted in solution containing $3.5 \%$ sodium chloride $(\mathrm{NaCl})$ and $18.2 \mathrm{M} \Omega \cdot \mathrm{cm}$ deionized water at $25^{\circ} \mathrm{C}$. The reference electrode used was $(\mathrm{Ag} / \mathrm{AgCl})$, and the counter electrode was platinum $(\mathrm{Pt})$. In the electrochemical cell, approximately $30 \mathrm{~mL}$ of the solution was in contact with an area of approximately $0.8 \mathrm{~mm}^{2}$ of the sample. The contact area with the sample was limited by the size of the cell used, so the weld region was studied as a single region without differentiation between LT-HAZ, HT-HAZ, and WM. Before the electrochemical tests, the samples were grounded and polished using the same procedures described in Section 2.2.1. In the software, the tests were adjusted in two steps; the first consisted in obtaining the value of the corrosion potential $\left(E_{c o r r}\right)$, in which the open-circuit potential technique was applied and where the solution was in contact with the sample and the value of potential measured. The measurement occurred until the software assumed that the voltage value was stable, so the value found was used as corrosion potential and used as a parameter for the second stage. The second step 
was started immediately after the corrosion potential was defined. To obtain the polarization curves, a value of $0.5 \mathrm{~V}$ below the corrosion potential was defined in the software as the start of the scan, and as a value of $1.5 \mathrm{~V}$ above the potential found to reverse the scan direction. Scan speed has been set to $1 \mathrm{mV} / \mathrm{s}$. Subsequently, the samples tested were submitted to scanning electron microscopy. The Zeiss scanning electron microscope, model EVO MA10 (Carl Zeiss, Stuttgart, Germany), which operates with lanthanum hexaboride (LaB6) filaments, was used to obtain micrographs using the secondary electron mode.

\section{Results and Discussion}

\subsection{Microstructural Characterization}

Due to the obtaining of many micrographs, for the three steels analyzed for three different heat inputs, it was chosen in this work to show the microstructural characterization of the regions for the three steels in the lower heat input and greater heat input, Figures 2-7. The subscript figures A, B, C, and D represent the base metal, LT-HAZ, HT-HAZ, and WM, respectively. In addition, Figures 2, 4 and 6 are related to welded steels with low heat input. Figures 3, 5 and 7 are related to welded steels with high heat input. In the micrographs, the ferrite appears as dark brown or dark and austenite as light brown. Different austenite morphologies arise, mainly in HT-HAZ and WM. The rolling direction is shown in Figure 2A for illustrative purposes only. The base metal microstructure, composed of lamellar structure and made up of alternating layers of ferrite and austenite, is shown in Figures 2A-7A. This region has not undergone any kind of alteration related to welding in these steels, and retains the traditional style for rolled DSS, as found in literature [22]. For example, for SAF 2205, for low heat input or high heat input (Figures 2A and 3A), the micrographs are similar. This behavior is also noted for SAF 2507 (Figures 6A and 7A). The visual difference is noted for SAF 2304 (Figures 4A and 5A), where ferrite lamellae are thicker for high heat input (Figure 5A), compared to low heat input (Figure 4A). Figure 2B shows that LT-HAZ, although it did not reach temperatures as high as HT-HAZ and WM (Figure 2C,D), where the material would completely enter the ferritic field during welding, there were some changes in its microstructure. This region has a very narrow range, which is a characteristic in DSS and SDSS welding, and since a low heat input of $0.5 \mathrm{~kJ} / \mathrm{mm}$ was used for SAF 2205, the weld depth was small, approximately $1 \mathrm{~mm}$. In the LT-HAZ shown in Figure 3B, the increase in the heat input changed the lamellar structure of ferrite and austenite, making them thicker when compared to Figure $2 \mathrm{~B}$. In Figure 4B, with the use of a low heat input, a very narrow HAZ band is again observed, formed by some small austenite islands in a ferritic matrix. In the LT-HAZ shown in Figure 5B, a thickness variation of ferrite and austenite phases is observed, compared to Figure 4B. In Figure 6B, in the LT-HAZ a slight variation in austenite thickness is observed in comparison to BM. As seen in the other steels (Figures 2B and 4B), a low heat input produces a very narrow range of the temperature transition region, with differences between regions being almost imperceptible. In the LT-HAZ, shown in Figure 7B, with a high heat input, an increase in austenite thickness is observed, compared to BM (Figure 7A). As a conclusion for LT-HAZ, with a significant increase in the applied heat input, that is, with slow cooling, phase growth is possible, which can be seen in Figures 3B, 5B, and 7B.

Figure 2C, HT-HAZ, shows the ferrite thickening and a tendency to change in grain morphology ("pancakes" for equiaxial) compared to Figure 2A,B. The presence of allotriomorphic austenite (AA) can be noticed, which is found in ferrite grain boundaries. Note also the Widmanstätten austenite (WA) that nucleates on grain boundaries ferrite or pre-existing allotriomorphic austenite and grows along specific planes of the matrix in sets of parallel laths. Inside ferrite grains, intragranular austenite nucleation was observed. Intragranular austenite (IA) precipitates at relatively low temperatures in the supersaturated ferritic matrix in nitrogen which is an austenite stabilizer, and nucleation is favored by supersaturation [23]. Figure 3C shows the HT-HAZ region with the formation of ferritic grains defined by allotriomorphic austenite with thicker agglomerates than those shown in Figure 2C, due to a slower cooling rate, making nucleation and growth of austenite possible. 
Figure $4 \mathrm{C}$ shows the presence of intragranular austenite and a ferritic grain defined by a low amount of allotriomorphic austenite. Figure 5C, HT-HAZ, notes the presence of well-defined ferritic grains and a larger agglomerate of allotriomorphic austenite, as well as an amount of intragranular austenite and larger laths of Widmanstätten austenite growing into the ferritic grain when compared to the low heat input, Figure 4C. Figure 6C shows HT-HAZ with the presence of ferritic grains slightly defined by allotrimorphic austenite. Also noted is a reasonable amount of intragranular austenite, similar micrograph to SAF 2205 with low heat input, Figure 2C. Some thin laths of Widmanstätten austenite growing from grain boundaries into ferrite grains are also identified. In the HT-HAZ region, observed in Figure 7C, it is possible to see large austenite agglomerates. An allotriomorphic austenite accumulation with amounts of intragranular austenite, generating regions with very high amounts of austenite. In the WM, indicated by Figure 2D, we can note equiaxial ferrite, with ferritic grains defined by allotrimorphic austenite. It is also noticed the presence of Widmanstätten austenite growing into the ferritic grain, as well as intragranular austenite. In the WM, shown in Figure 3D, there are larger ferrite grains (compared to Figure 2D), in addition to intragranular austenite and Widmanstäten austenite. Figure 4D shows a format of the ferritic grain in the WM almost columnar, and visibly the lowest amount of austenite compared to the other regions of this steel and SAF 2205, Figure 2D; only austenite in the allotriomorphic form, delimiting the grain size and a small amount of intragranular austenite. Due to a faster cooling rate, justified by the low heat input employed and a lower amount of alloying elements that stabilize austenite, when compared to SAF 2205, the austenite fraction is noticeably smaller compared to Figure 2D. Figure 5D (WM), shows a larger amount of austenite and that it is thicker when compared to the same region of the low heat input, Figure 4D, evidencing the effect that slower cooling rate has on the nucleation and growth of the austenite. WM presents both the Widmanstätten austenite, which nucleates from the allotriomorphic austenite present in the grain boundaries ferritic, as well as intragranular austenite. In WM, Figure 6D shows a micrograph similar to Figure 2D, SAF 2205, previously analyzed, with large amounts of ferrite. Following the WM, shown in Figure 7D, we can immediately see: columnar ferritic grains and a large amount of Widmanstätten austenite, some laths so long that they cross the ferritic grain. Table 3 presents a summary of the main microstructural changes for each steel considered in this investigation. The microstructural changes can be compared for each zone. In all heat inputs, low or high, i.e., with fast or slow cooling rate, for all the steels analyzed, the presence of intermetallic phases, such as sigma phase among others, was not noticed. In order to support the phase formation discussions, a mathematical model able to predict the transient temperature distribution and heating/cooling rates for the experimental condition used on the autogenous TIG process under different heat inputs. Figure 8A-C show the spatial distribution of the cooling rates for the higher heat input of the welding procedures used for SAF 2304, 2205, and 2507, respectively, just at the time when the welding torch current is interrupted and heat supply is finished. As expected, the cooling rates developed during the critical periods of the welding procedures for the SAF 2304, 2205, and 2507 presented moderate values, as shown in Figure 8A-C, despite the fact that the SAF 2507 plate has shown a wider region with higher cooling rates. The maximum cooling rates are about $5{ }^{\circ} \mathrm{C} / \mathrm{s}$ during a period of around $60 \mathrm{~s}$ within the range of deleterious phase formations, such as sigma and the chromium nitrate. Therefore, the residence time that could allow the formation of these intermetallic phases and precipitates are much higher [1]. Thus, we can conclude that the amount of phase that could be formed would be negligible, which justifies the non-detection on these phases on the microstructural analysis carried out in this work. A simple model proposed in the literature [24], Equation (5), was applied using the cooling rates experienced during welding procedure where temperature remains around $850{ }^{\circ} \mathrm{C}$, for the sigma phase prediction of the steels and indicated that the values are of the order of $0.05 \%$, which is negligible for all conditions developed during the procedure carried out in this investigation.

$$
\sigma=0.33 \times(\text { Cooling rate })^{-1.05}
$$




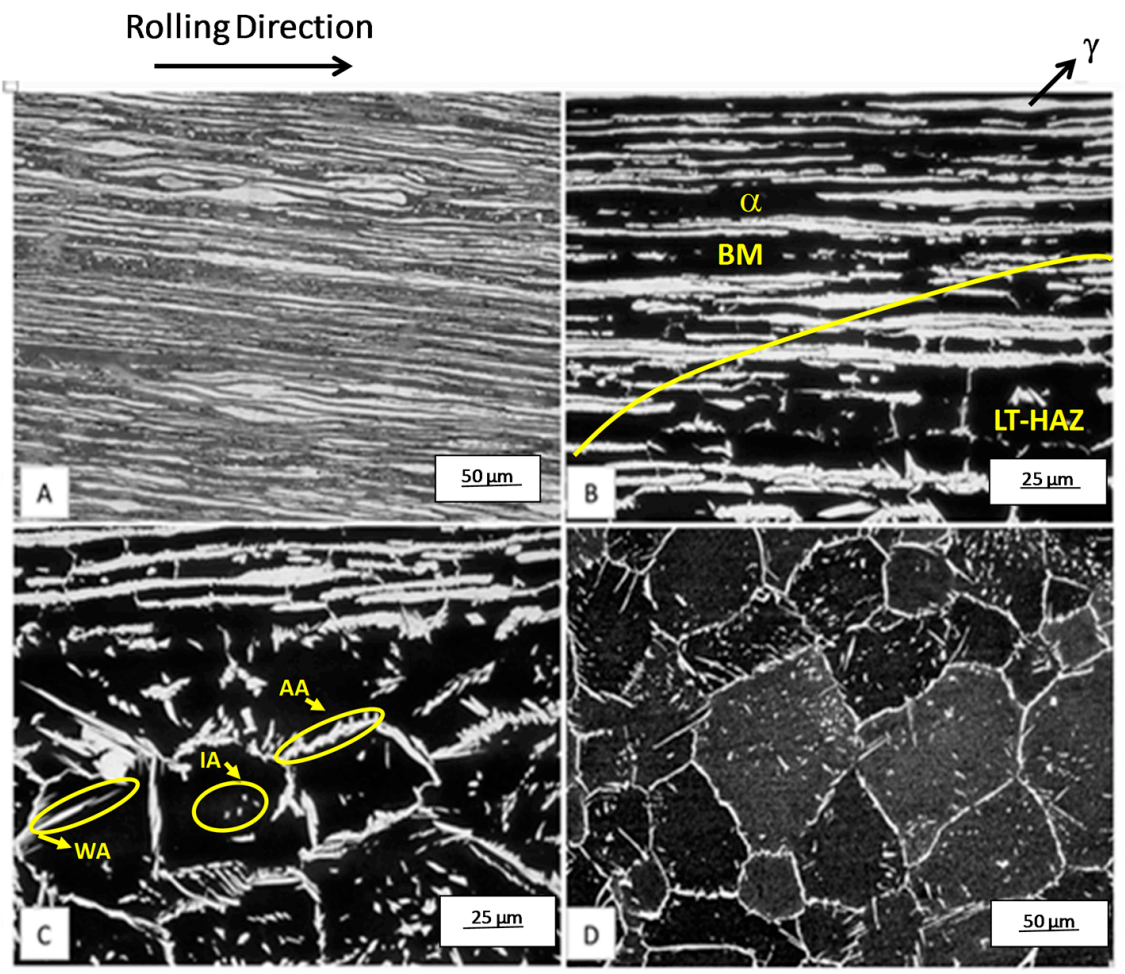

Figure 2. SAF 2205-Low heat input: (A) base metal (BM); (B) BM/low temperature heat affected zone (LT-HAZ); (C) high temperature heat affected zone (HT-HAZ); (D) weld metal (WM); Beraha Etching. Where: $\alpha$ (ferrite-dark/dark brown), $\gamma$ (austenite-light brown), WA-Widmanstätten Austenite, IA-Intragranular Austenite, AA-Allotriomorphic Austenite.

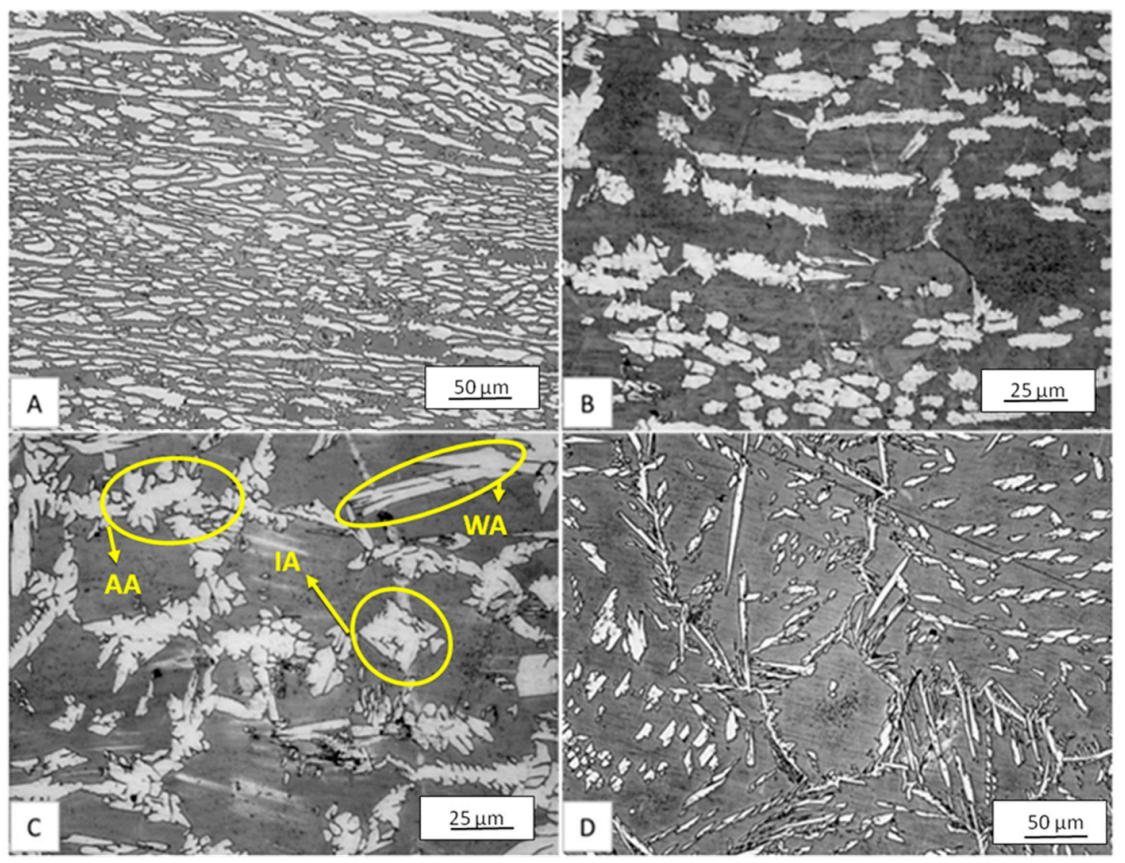

Figure 3. SAF 2205-High heat input: (A) BM; (B) LT-HAZ; (C) HT-HAZ; (D) WM; Beraha Etching. Where: ferrite-dark/dark brown, austenite-light brown, WA-Widmanstätten Austenite, IA-Intragranular Austenite; AA-Allotriomorphic Austenite. 


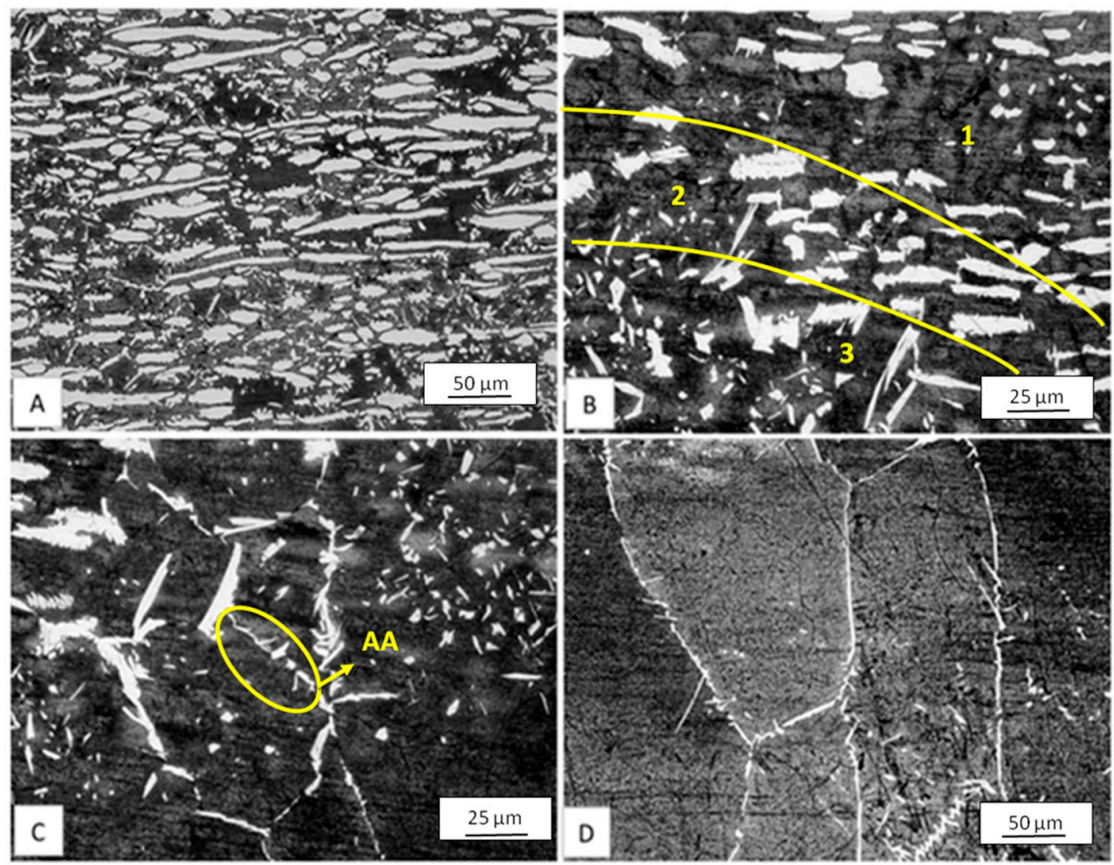

Figure 4. SAF 2304-Low heat input: (A) BM; (B) 1-BM; 2-LT-HAZ; 3-HT-HAZ; (C) HT-HAZ; (D) WM; Beraha Etching. Where: ferrite—dark/dark brown, austenite-light brown, AA-Allotriomorphic Austenite.

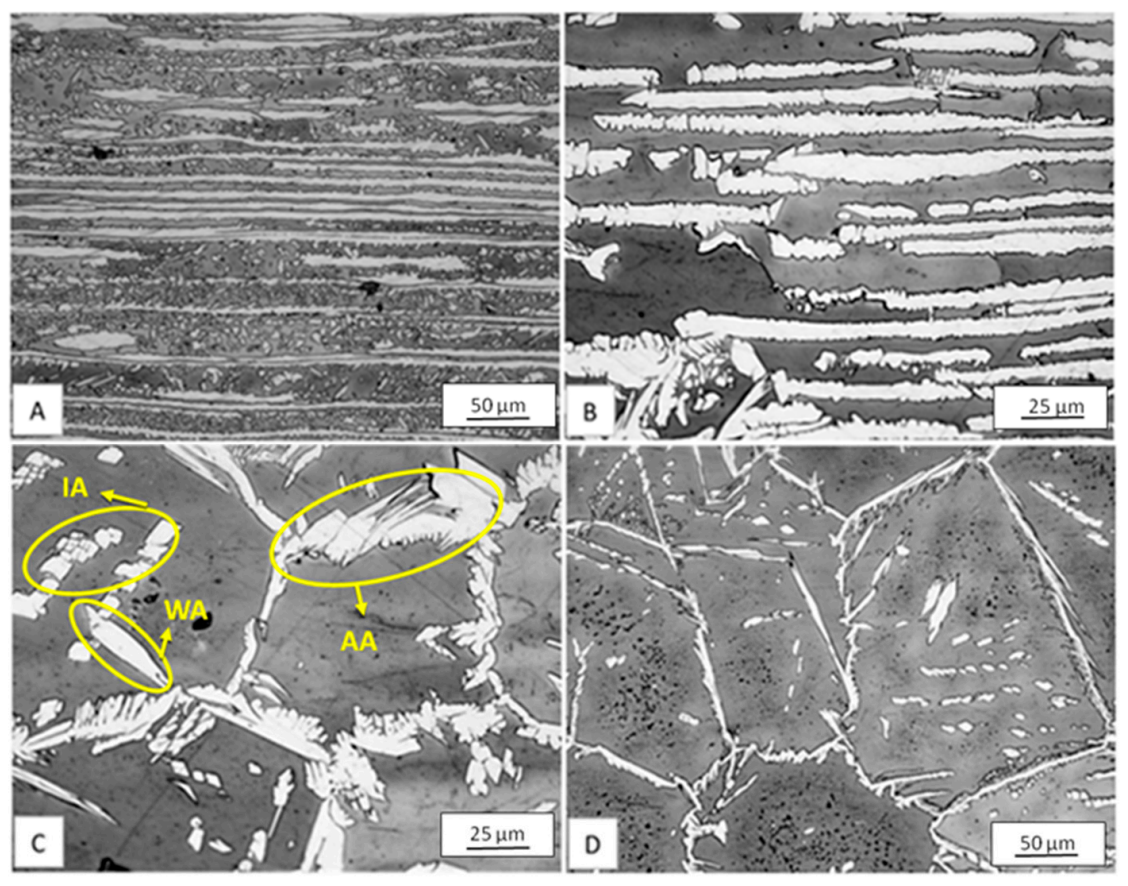

Figure 5. SAF 2304-High heat input: (A) BM; (B) LT-HAZ; (C) HT-HAZ; (D) WM; Beraha II Etching. Where: ferrite—dark/dark brown, $\gamma$ austenite-light brown, WA-Widmanstätten Austenite, IA-Intragranular Austenite, AA-Allotriomorphic Austenite. 


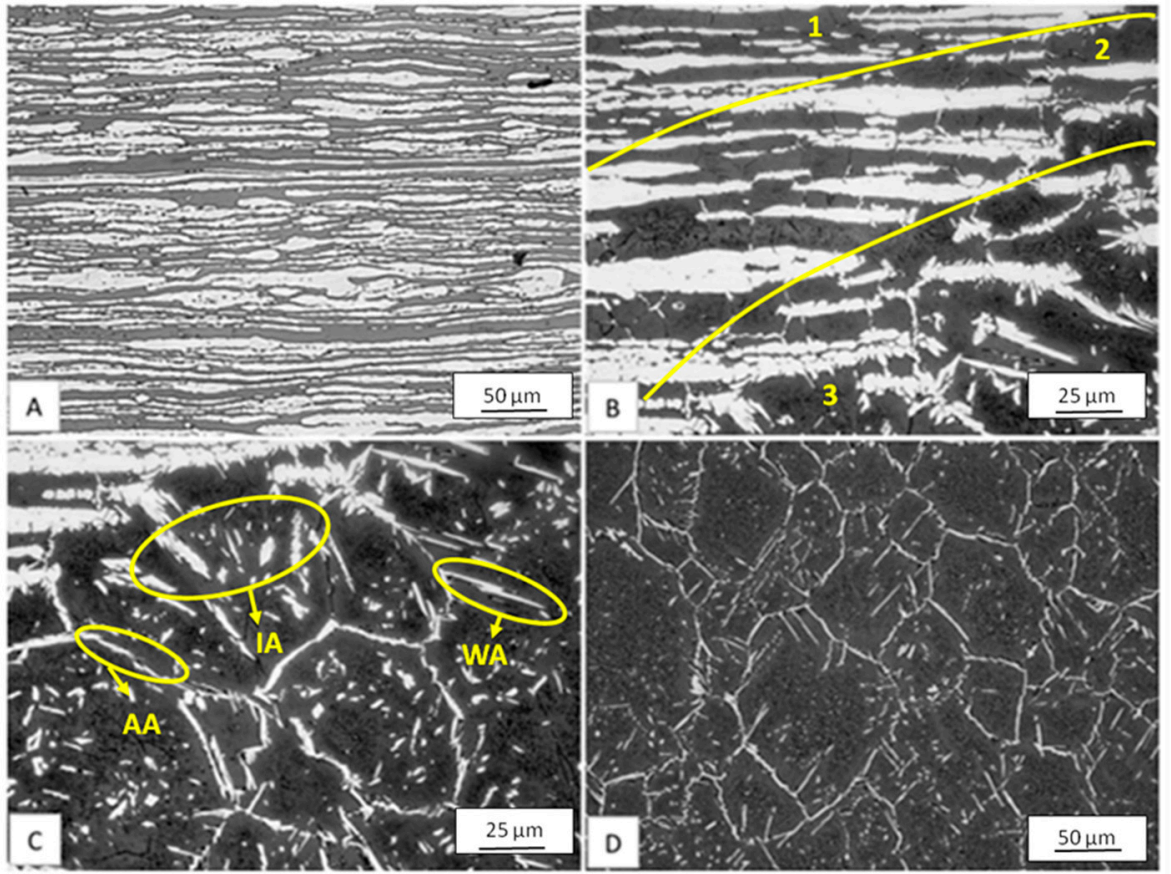

Figure 6. SAF 2507-Low heat input: (A) BM; (B) 1-BM; 2-LT-HAZ; 3-HT-HAZ; (C) HT-HAZ; (D) WM; Beraha II Etching. Where: ferrite-dark/dark brown, austenite-light brown, WA-Widmanstätten Austenite, IA-Intragranular Austenite, AA-Allotriomorphic Austenite.

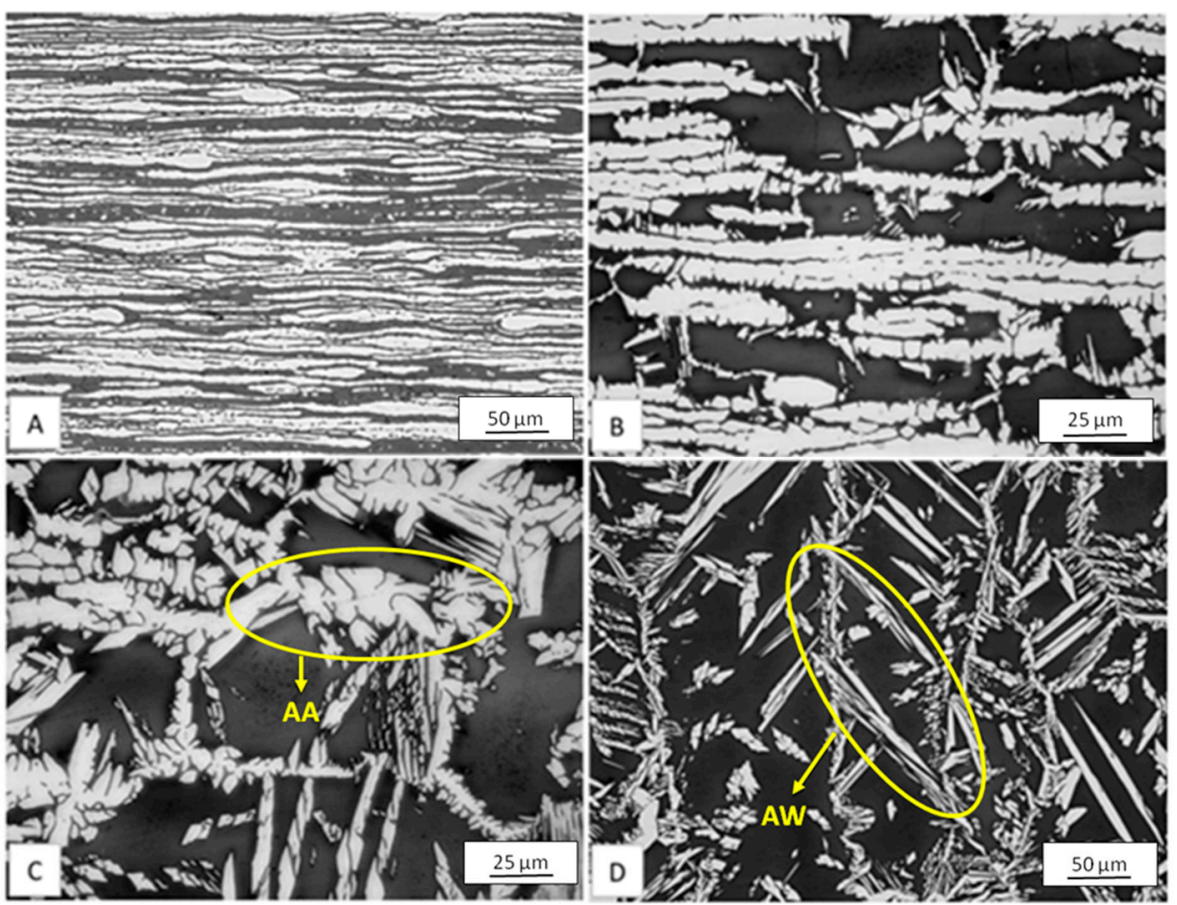

Figure 7. SAF 2507-High heat input: (A) BM; (B) LT-HAZ; (C) HT-HAZ; (D) WM; Beraha Etching. Where: ferrite—dark/dark brown, austenite-light brown, WA-Widmanstätten Austenite, AA-Allotriomorphic Austenite. 


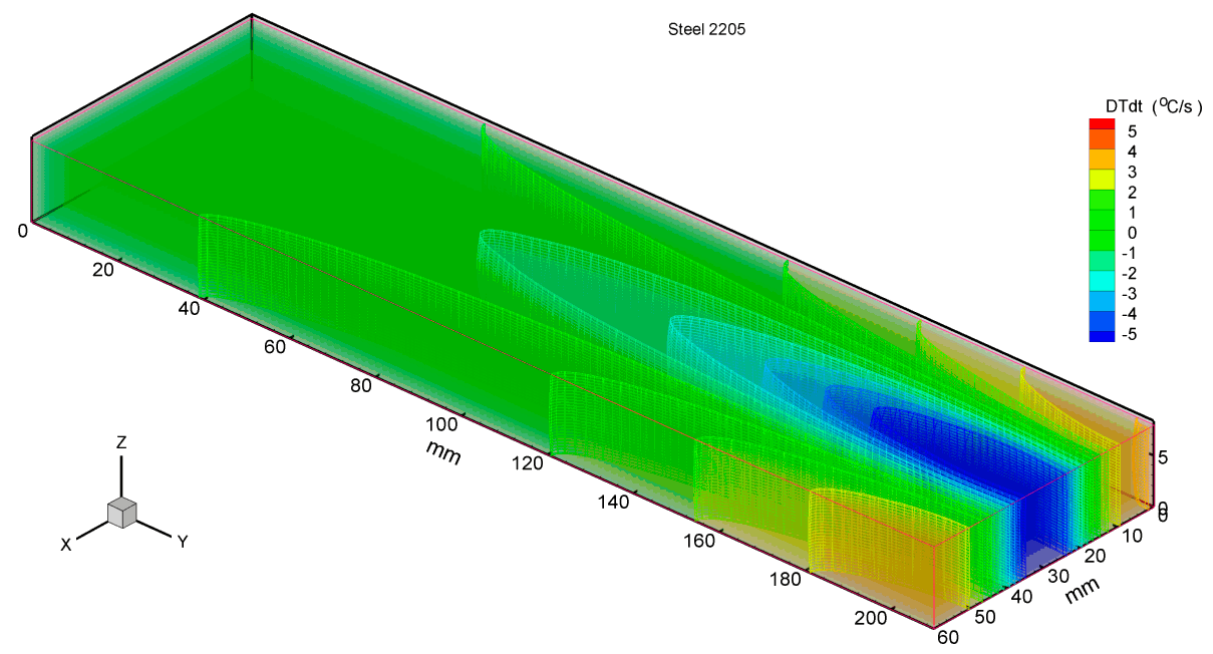

(A) SAF 2205

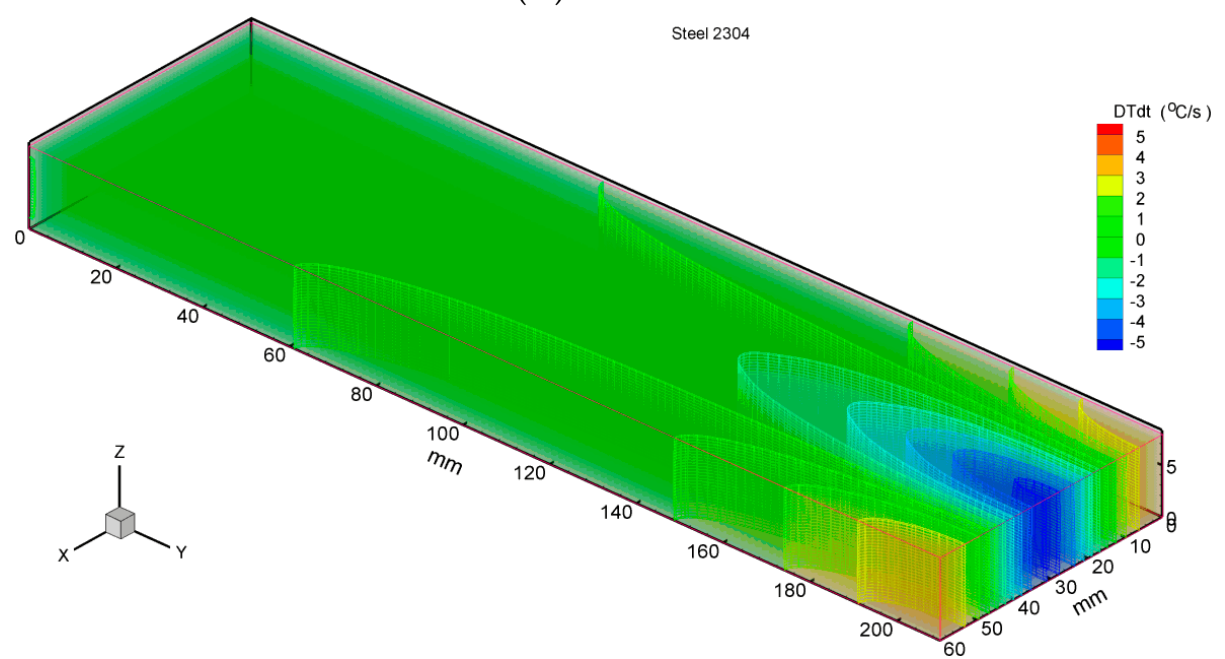

(B) SAF 2304

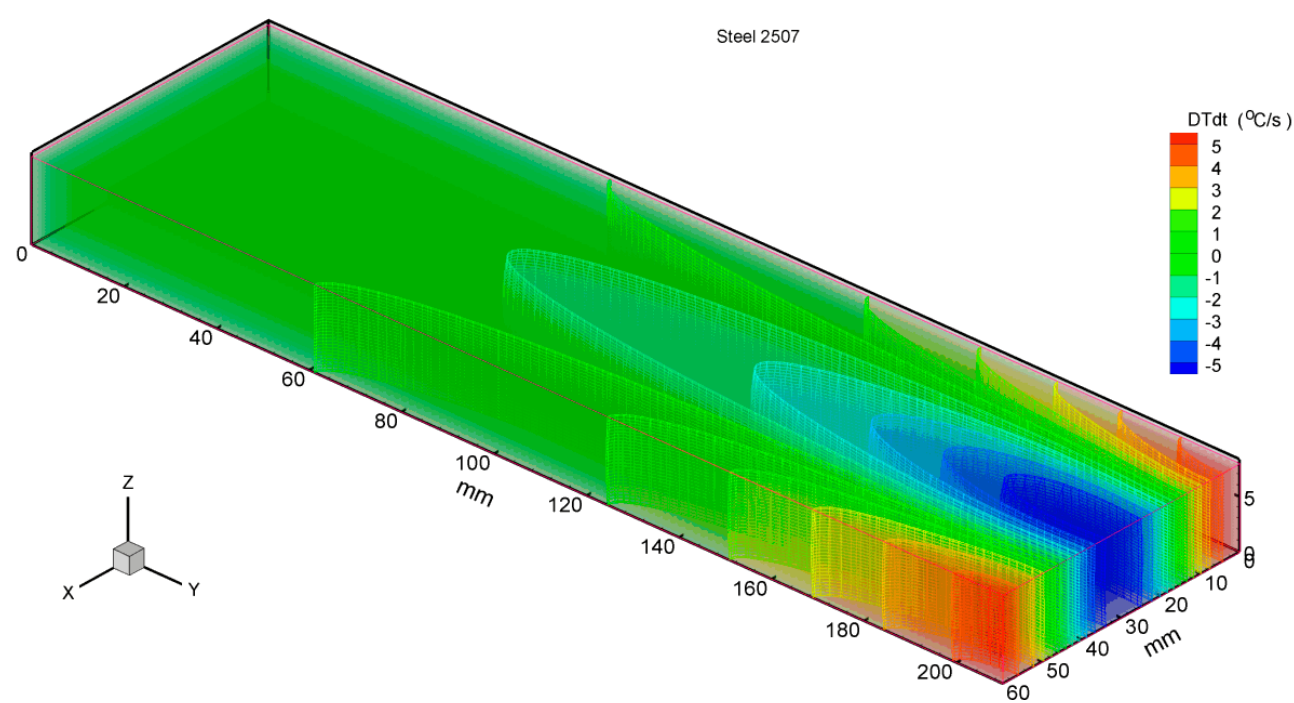

(C) SAF 2507

Figure 8. Heating/cooling rates distribution, (A) SAF 2205, (B) SAF 2304, and (C) SAF 2507 plates for the higher heat input at the end of the welding procedure. 
Table 3. Summary of the main microstructural changes for each steel shown in Figures 2-7. A more detailed discussion is found in the text. F-Ferrite; A-Austenite; AA-Allotriomorphic Austenite; WA-Widmanstätten Austenite, IA-Intragranular Austenite.

\begin{tabular}{clllc}
\hline \multirow{2}{*}{ Region } & \multicolumn{1}{c}{2205} & \multicolumn{1}{c}{ 2304 } & \multicolumn{1}{c}{ 2507 } & Heat Input \\
\hline \multirow{2}{*}{ BM } & F and A lamellar & F and A lamellar & F and A lamellar & Low \\
\cline { 2 - 5 } & F and A lamellar & F and A lamellar. F thicker & F and A lamellar & High \\
\hline \multirow{2}{*}{ LT-HAZ } & $\begin{array}{l}\text { F and A lamellar. } \\
\text { very narrow range }\end{array}$ & $\begin{array}{l}\text { F matrix. A islands. very } \\
\text { narrow range }\end{array}$ & $\begin{array}{l}\text { F and A thicker than BM. } \\
\text { very narrow range }\end{array}$ & Low \\
\cline { 2 - 5 } & F and A lamellar. F thicker & F and A thicker & F and A thicker than BM & High \\
\hline \multirow{2}{*}{ HT-HAZ } & $\begin{array}{l}\text { F thickening. Tendency to } \\
\text { change in grain morphology } \\
\text { ("pancakes" for equiaxial) } \\
\text { compared to BM and LT-HAZ. } \\
\text { A Morphology: AA, WA, IA }\end{array}$ & $\begin{array}{l}\text { F grain defined by a low } \\
\text { amount of AA. Presence of IA }\end{array}$ & $\begin{array}{l}\text { F gains slightly defined by } \\
\text { IA and WA. Similar 2205. }\end{array}$ & Low \\
\cline { 2 - 5 } & $\begin{array}{l}\text { F defined by AA with thicker } \\
\text { agglomerates (AA, WA, IA) }\end{array}$ & $\begin{array}{l}\text { Well-defined F grains and } \\
\text { a larger agglomerate of AA. } \\
\text { IA and WA growing. }\end{array}$ & $\begin{array}{l}\text { F grains and large A } \\
\text { agglomerates. AA and IA }\end{array}$ & High \\
\hline \multirow{2}{*}{ WM } & $\begin{array}{l}\text { Equiaxial F defined by AA. } \\
\text { Presence of WA and IA }\end{array}$ & $\begin{array}{l}\text { F grain almost columnar. } \\
\text { Lowest amount of A }\end{array}$ & Similar SAF 2205 & Low \\
\cline { 2 - 5 } & $\begin{array}{l}\text { Larger F grains. Presence of } \\
\text { AA, WA and IA }\end{array}$ & $\begin{array}{l}\text { F and A thicker compared to } \\
\text { low heat input. Presence of } \\
\text { AA, WA, IA }\end{array}$ & $\begin{array}{l}\text { Columnar F grains and } \\
\text { a large amount of WA }\end{array}$ & High \\
\hline
\end{tabular}

\subsection{Volumetric Fraction of Ferrite}

In all figures of this subitem, a line was inserted in the range of 70\% of the quantified phase, in this case the ferrite. This range is in reference to the standard Norsok [20], which recommends a minimum of $30 \%$ of austenite so that welded joints are qualified in pipe inspections.

In the comparison of the volumetric fraction of ferrite by heat input, it can be seen from Figure 9 that when the welding procedure uses a low heat input, there is an evident growth of the ferrite fraction in the weld region. It can be seen that SAF 2304-which contains lower levels of alloying elements than SAF 2205 and SAF 2507, such as Ni and N that stabilize the austenite, accompanied by a fast cooling rate-shows an excessive increase of the ferrite fraction. SAF 2205 and SAF 2507, with the fast cooling rate, do not maintain the ferrite-austenite balance in HT-HAZ and WM. It can be seen from Figure 10 that the use of a medium heat input increases the austenite fraction formed, resulting in a decrease in ferrite, mainly in the HAZ (LT and HT). Again, the effect of the alloying elements such $\mathrm{Ni}$ and $\mathrm{N}$ in the stabilization of the austenite is evident when comparing the result of SAF 2304 with the others. However, the ferrite fractions obtained in HT-HAZ and WM for SAF 2205 and WM for SAF 2507 are still considered insufficient. Figure 11 shows the influence of the use of a high heat input on the ferrite volumetric fraction. In other words, with a slow cooling rate, greater austenite formation is possible. Thus, the volumetric fraction of ferrite for SAF 2205 and SAF 2507 remained within the limit until HT-HAZ. Despite a high heat input, SAF 2304 has a high ferrite value ( $>70 \%)$ in HT-HAZ and WM. Although SAF 2507 and SAF 2205 have very similar compositions, SAF 2507, considered a superduplex, has higher $\mathrm{Ni}$ and $\mathrm{N}$ contents than SAF 2205. This difference is evident when observing the WM of these steels, where only the SAF 2507 remained within the acceptable limit reported by the standard. Results presented here corroborate with those observed in the micrographs presented in Section 3.1. 


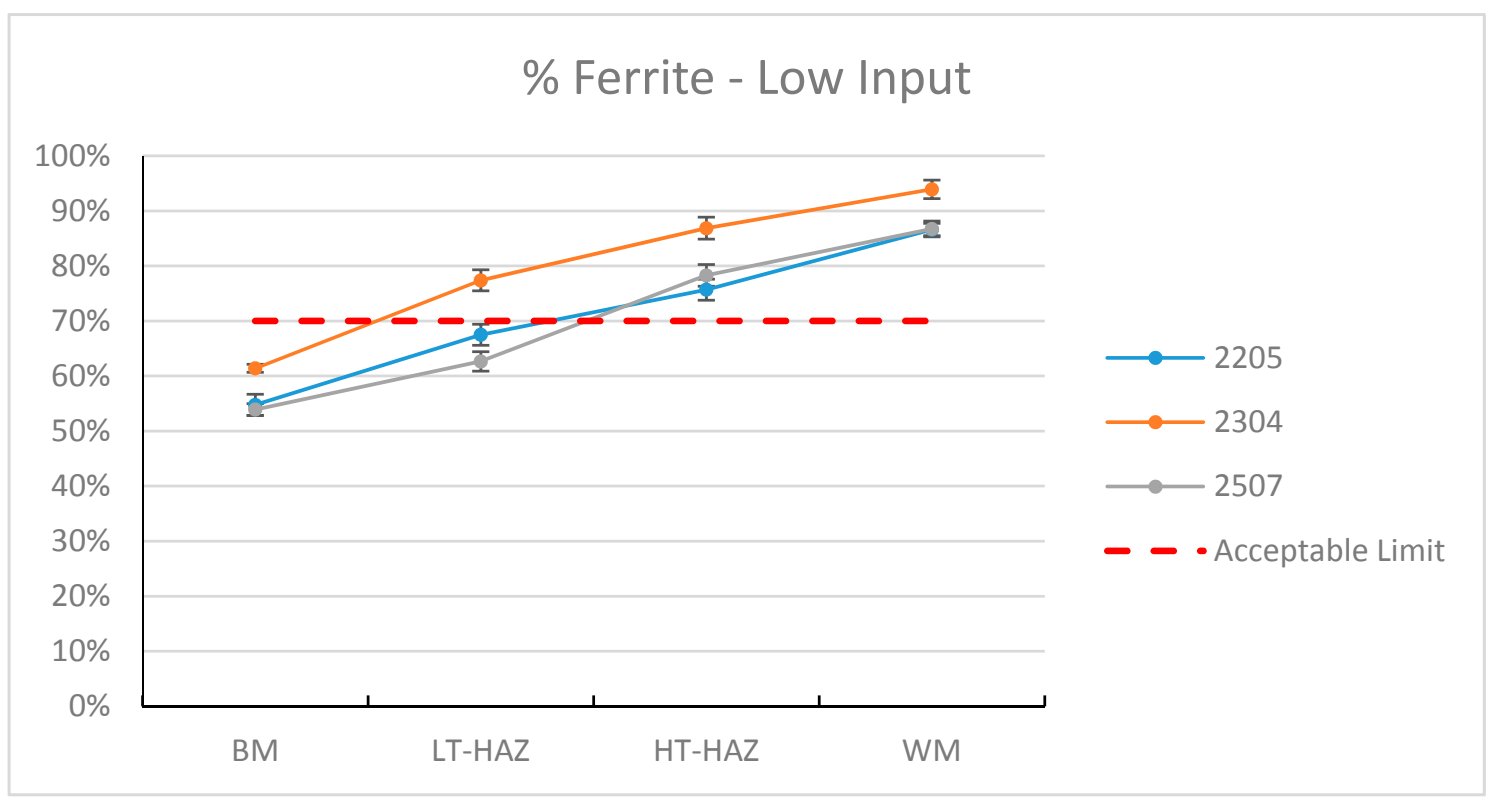

Figure 9. Volumetric Fraction of ferrite-Low Input: BM; LT-HAZ; HT-HAZ; WM.

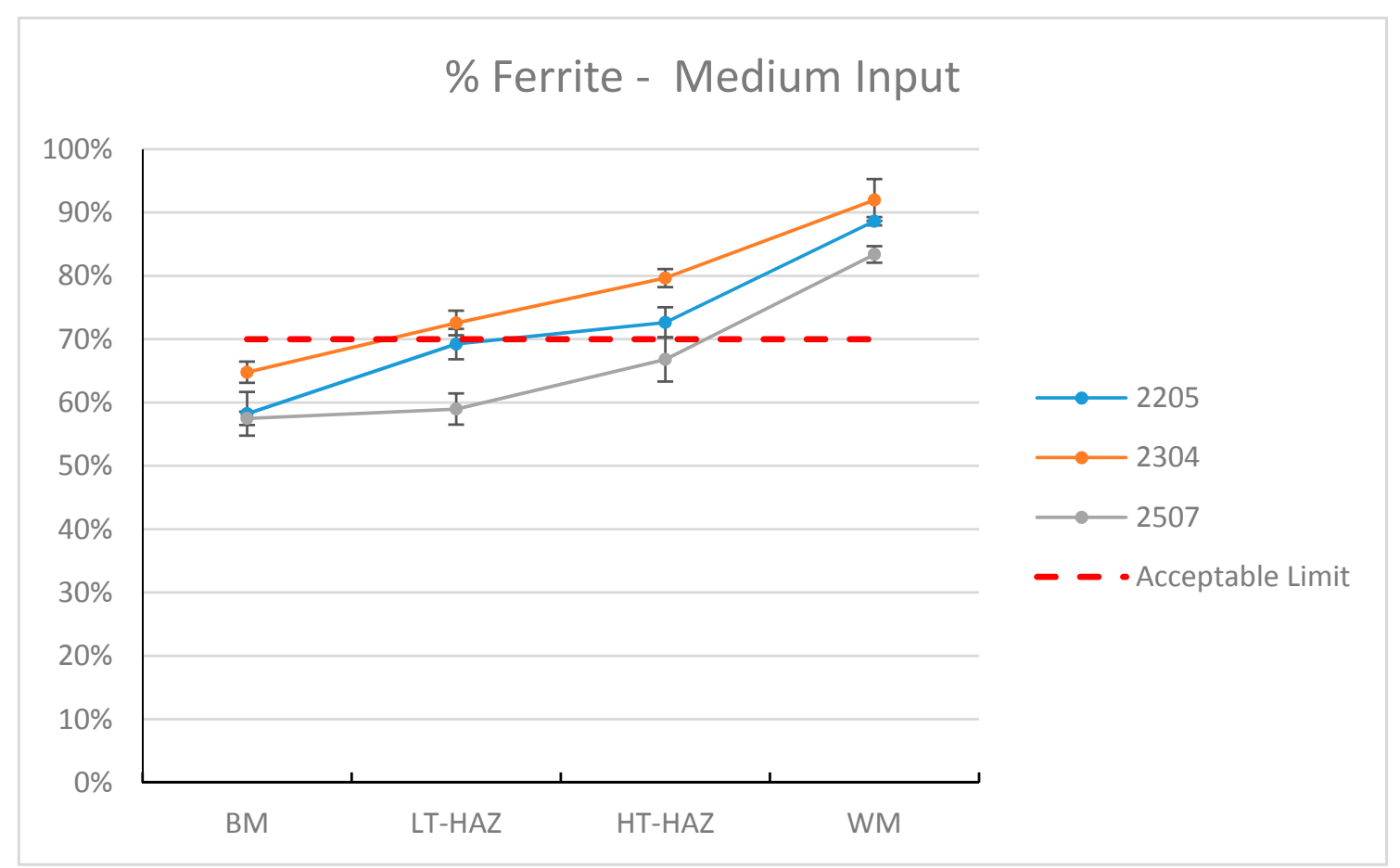

Figure 10. Volumetric Fraction of ferrite-Medium Input: BM; LT-HAZ; HT-HAZ; WM.

\subsection{Mechanical Properties}

Although the ferrite fraction is a prime factor for the "duplex" classification, mechanical properties such as hardness and energy absorbed in impact tests should be taken into account. These results are presented here. 


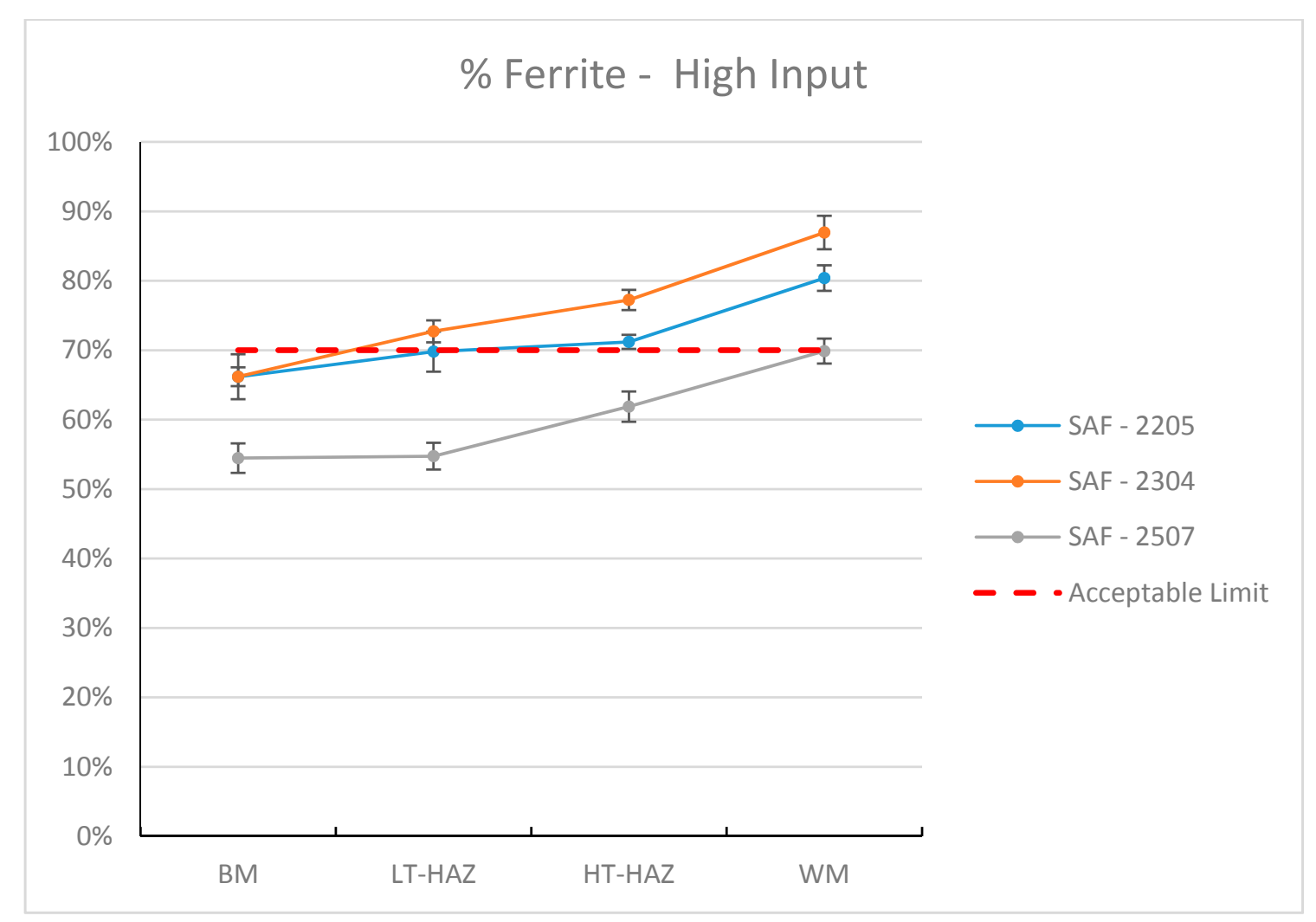

Figure 11. Volumetric Fraction of ferrite-High Input: BM; LT-HAZ; HT-HAZ; WM.

\subsubsection{Vickers Hardness}

According to Figure 12, no relevant variation in the hardness obtained for SAF 2205 is observed. The values were maintained in the range of $250 \mathrm{HV}$, from the base metal to the weld metal, regardless of the heat input used. The hardness profile obtained for SAF 2304, shown in Figure 13, shows a hardness peak in the transition region between WM and BM in the weld performed with a low heat input. This increase in hardness can be attributed to the significant ferrite presence in this region (Figure 9). In the other heat inputs, it is possible to observe a constancy in the results with values close to $220 \mathrm{HV}$ in all the regions. Figure 14 shows the hardness profile of SAF 2507. In the WM region for high heat input, a slight decrease in the measured hardness value is noted. This is related to the amount of ferrite and austenite present in this region, due to the fact that among the three steels, SAF 2507 obtained the highest amount of austenite in WM (Figure 11). In the WM region for low heat input, the behavior is the inverse of the previously mentioned, considering that with a lower heat input a higher volumetric fraction of ferrite was obtained, which would justify the increase of the hardness in the WM region. At the center of the weld bead, the distance to the base metal on both sides of the weld bead was calculated. As the depth of the weld bead was higher for the high heat input compared to the medium heat input, the distance of the center of the weld bead to the base metal was lower for the high heat input compared to the medium heat input, which can be seen in Figures 12-14. 


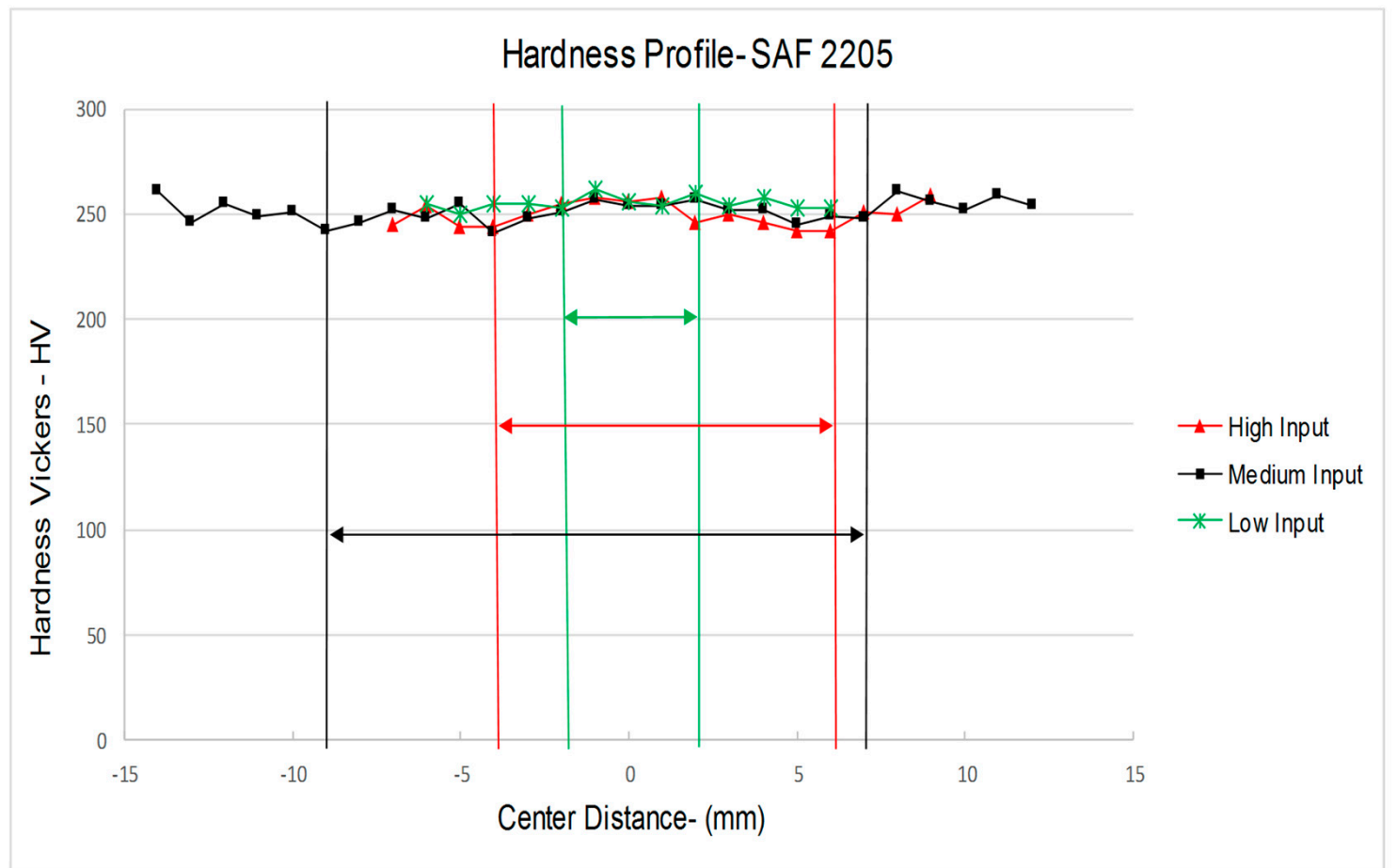

Figure 12. Vickers Hardness profile-SAF 2205. The arrows represent the distance from the weld center. i.e., width of WM. Values were measured from the base metal to the base metal, i.e., BM, LT-HAZ, HT-HAZ, WM, HT-HAZ, LT-HAZ, BM.

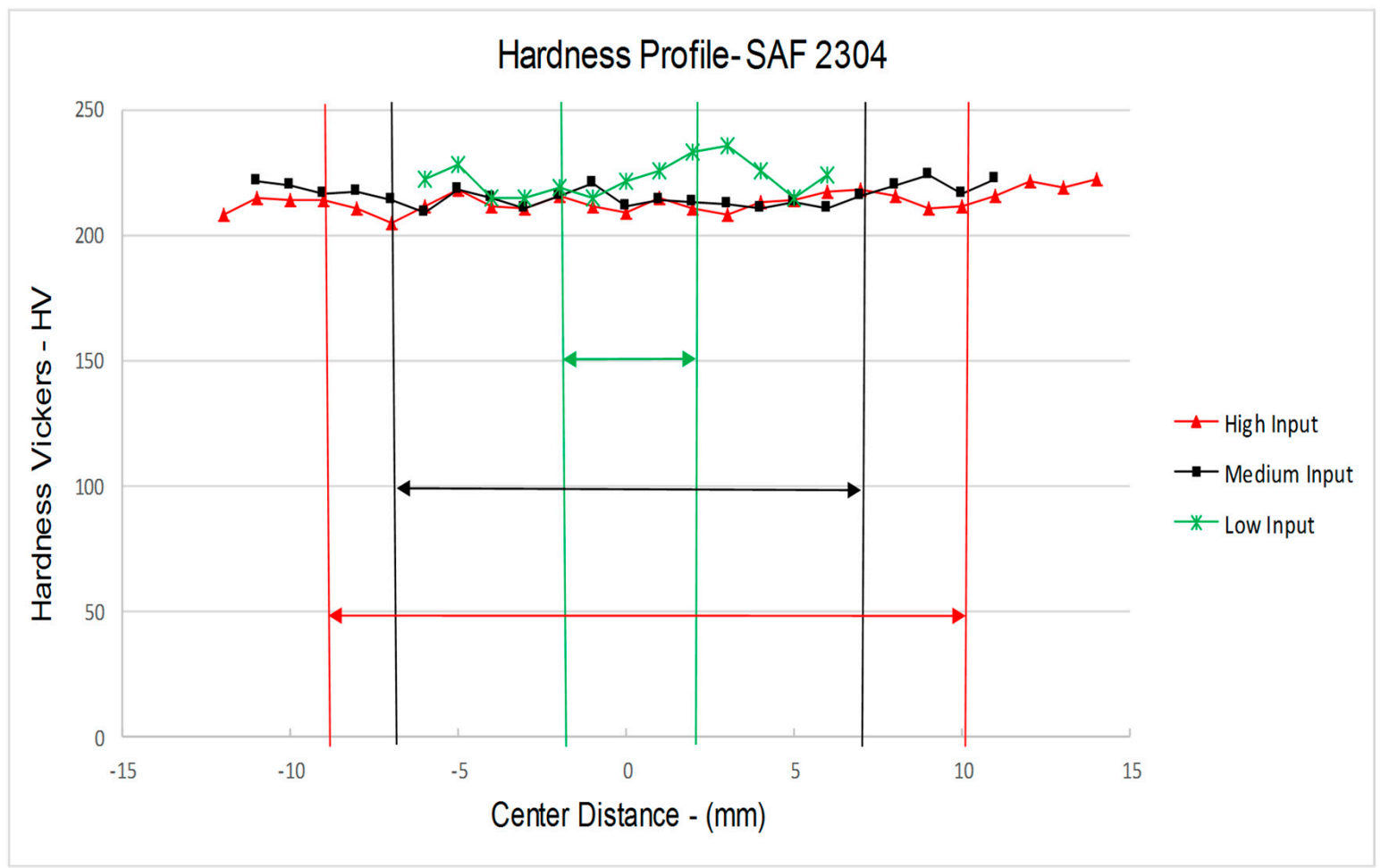

Figure 13. Vickers Hardness-SAF 2304. The arrows represent the distance from the weld center. i.e., width of WM. Values were measured from the base metal to the base metal, i.e., BM, LT-HAZ, HT-HAZ, WM, HT-HAZ, LT-HAZ, BM. 


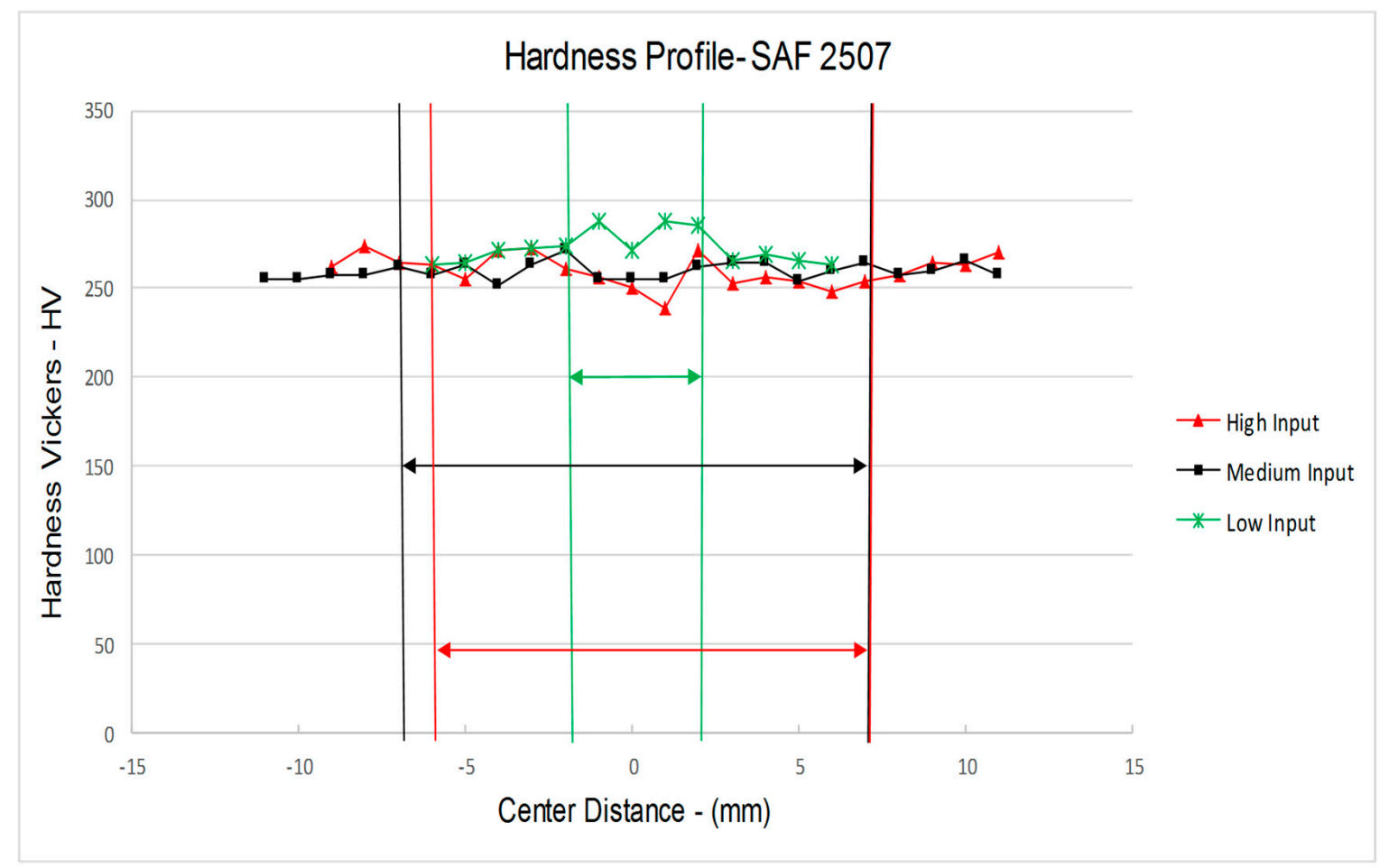

Figure 14. Vickers Hardness-SAF 2507. The arrows represent the distance from the weld center. i.e., width of WM. Values were measured from the base metal to the base metal, i.e., BM, LT-HAZ, HT-HAZ, WM, HT-HAZ, LT-HAZ, BM.

\subsubsection{Charpy Impact Test}

Figure 15 shows an acceptance limit for the values obtained in the Charpy-V impact test at $-46{ }^{\circ} \mathrm{C}$. This acceptance limit of $27 \mathrm{~J}$, as well as the temperature of the test, is based on the Norsok standard [20]. Each point shown in the graph corresponds to an average energy absorbed by the steels during the fracture, since each steel was tested with three specimens for each heat input used.

It is immediately observed that SAF 2304 is the most fragile, with the absorbed energy lower than the acceptance limit proposed by the standard. Because it is steel with lower $\mathrm{N}$ and Ni contents, it has already been noted in previous results that the region tested, i.e., WM, is very poor in austenite (Figures 10 and 11). As is well known [25], austenite (FCC) has a great influence on the impact test result, since it is has more toughness than ferrite (BCC) and provides a higher absorbed energy. SAF 2205 shows that despite having more absorbed energy than the acceptance limit, the energy value for welded samples with high heat input was very close to the limit of the standard. The samples welded with a medium heat input obtained values well above the limit. SAF 2507 presented similar behavior to SAF 2205. Lower energy absorbed for high heat input compared to medium heat input, but to both heat inputs, energy absorbed by SAF 2507 is superior to SAF 2205. A possible explanation for higher energy absorbed with medium heat input would be the amount of WA formed in the steels in WM because, as found by other authors, the differences in the toughness cannot be explained only by the volumetric fraction of ferrite [26]. For SAF 2205 with medium heat input, the volumetric fraction (\%) of WA formed was $4.0 \pm 2.1$ and for high input was $7.3 \pm 2.3$; for SAF 2507 with medium heat input the volumetric fraction (\%) of WA formed was $2.7 \pm 0.7$ and for high heat input was $8.6 \pm 2.0$. It is clear that, for high heat input, WA formed is higher than for medium heat input, which worsens the toughness, and that also may have caused the fall in the value of absorbed energy, but still above that established by the standard. In theory, they would be enabled for use, considering only this property. 


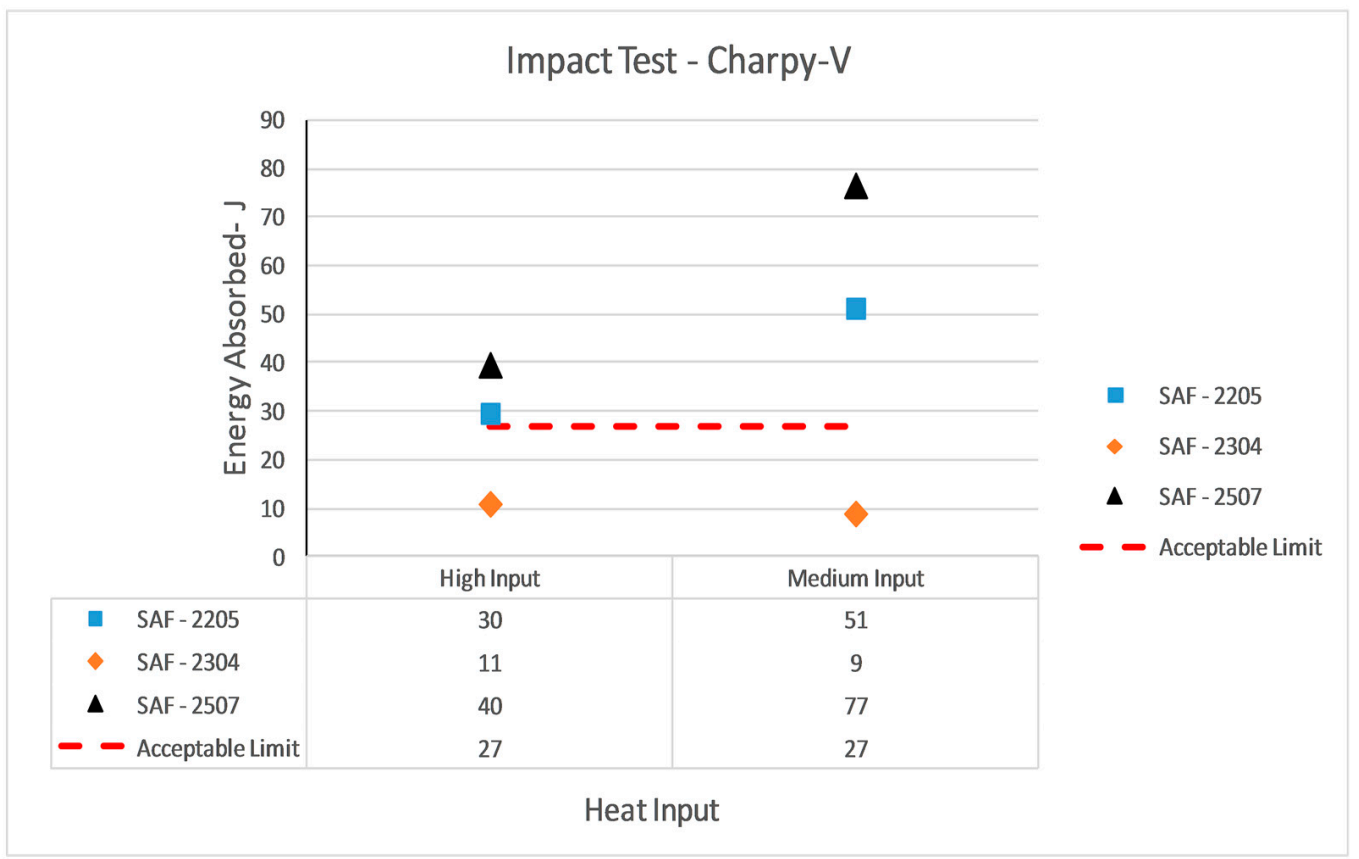

Figure 15. Energy absorbed by the steels. The errors measured in the samples are smaller than the symbol used in Figure 15 and are not shown.

\subsection{Electrochemical Tests}

Table 4 shows the corrosion potential $\left(E_{c o r r}\right)$ value obtained after the cyclic polarization for base metal and weld region. The corrosion resistance was associated with corrosion potential and the higher this value, the more corrosion resistant is the metallic material.

Table 4. $E_{\text {corr }}(\mathrm{V})$ for DSS and SDSS (wt \%).

\begin{tabular}{ccccc}
\hline SAF & & Low Input & Medium Input & High Input \\
\hline \multirow{2}{*}{2205} & BM & 0.244 & 0.284 & 0.004 \\
& Weld & 0.256 & 0.282 & 0.178 \\
\hline \multirow{2}{*}{2304} & BM & 0.024 & -0.182 & -0.274 \\
& Weld & -0.267 & -0.036 & -0.051 \\
\hline \multirow{2}{*}{2507} & BM & 0.269 & 0.258 & 0.010 \\
& Weld & 0.096 & 0.073 & 0.302 \\
\hline
\end{tabular}

It is possible to observe in Table 4 that SAF 2205 and SAF 2507 are more corrosion resistant than SAF 2304. Figure 16 shows the cyclic polarization results for SAF 2507 (high input) on base metal region and weld region. Other steels presented similar polarization curves, all of them with a very characteristic appearance as indicated in Figure 16, where it is possible to observe one cathodic current decreasing up to corrosion potential. After the corrosion potential, at high potentials, the passive region was observed and the oxide film thickness increases in this potential region. At approximately $1.1 \mathrm{~V}$, an increase in current is observed that can be associated with the localized corrosion. The potential scan was reversed at potential values higher than $1.1 \mathrm{~V}$, presenting a positive hysteresis loop indicating that the damaged passive film is not restored and localized corrosion has started. After this, the current density of steel decreased exponentially as the potential decreased up to repassivation potential. The potential corrosion was obtained from this curve and it was shown in the Table 4. Figure 16 and Table 4 show that the weld region presented the highest $E_{\text {corr }}$ value for SAF 2507, evidencing that the weld increased the corrosion resistance in comparison to BM. This behavior is observed by other authors in the literature with welding by filler metal [7]. In our experiments, thermal cyclic itself applied on the sample in the 
autogenous welding was sufficient for an improvement in the corrosion resistance. The ferrite-austenite balance has been maintained, and this is clearer in SAF 2507 with high heat input. Once again, evidence that high heat input is beneficial to the corrosion resistance of DSS and SDSS.

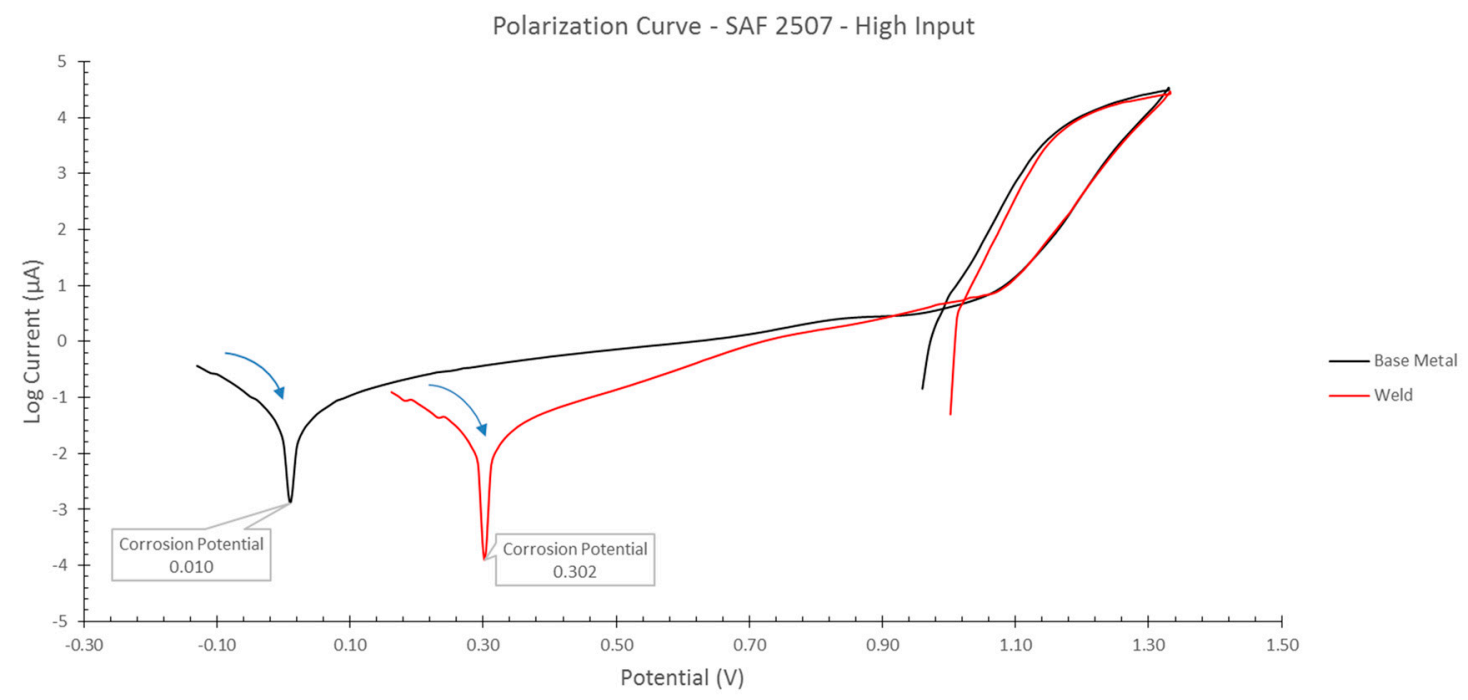

Figure 16. Polarization Curve-SAF 2507-High Heat Input. Base Metal and Weld region.

For comparison purposes, the micrograph of SAF 2304 welded with medium input after corrosion test was shown in Figure 17. It is possible to observe large holes on the surfaces associated with the formation and increase of the pits on the sample surface. Conversely, the microstructural characteristics of SAF 2507 (Figure 18), welded with high input, the BM, as well as the weld region presented good features, evidencing its high corrosion resistance.

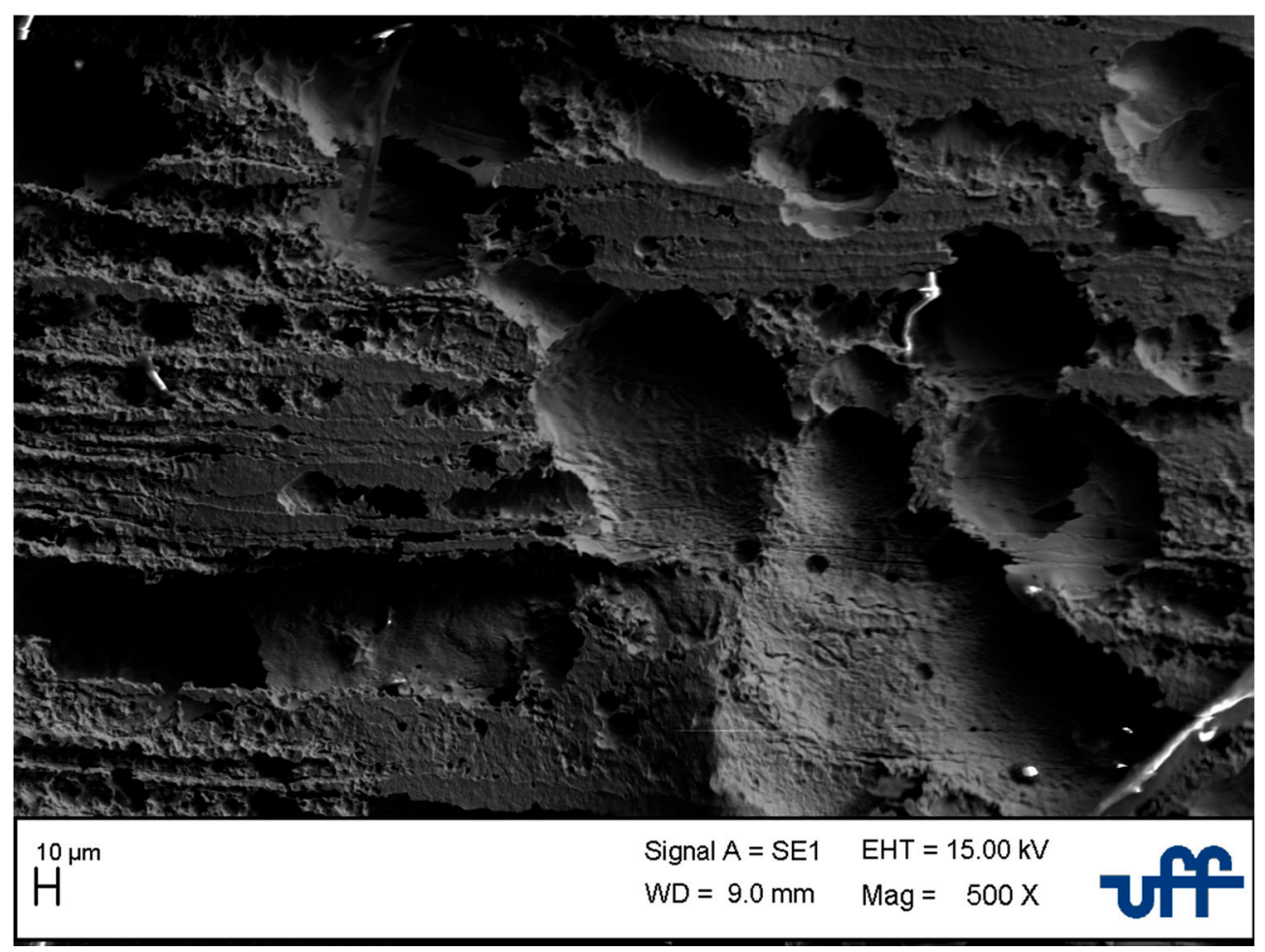

Figure 17. Microstructural aspect after electrochemical test. SAF 2304-Medium heat input. Base metal. 


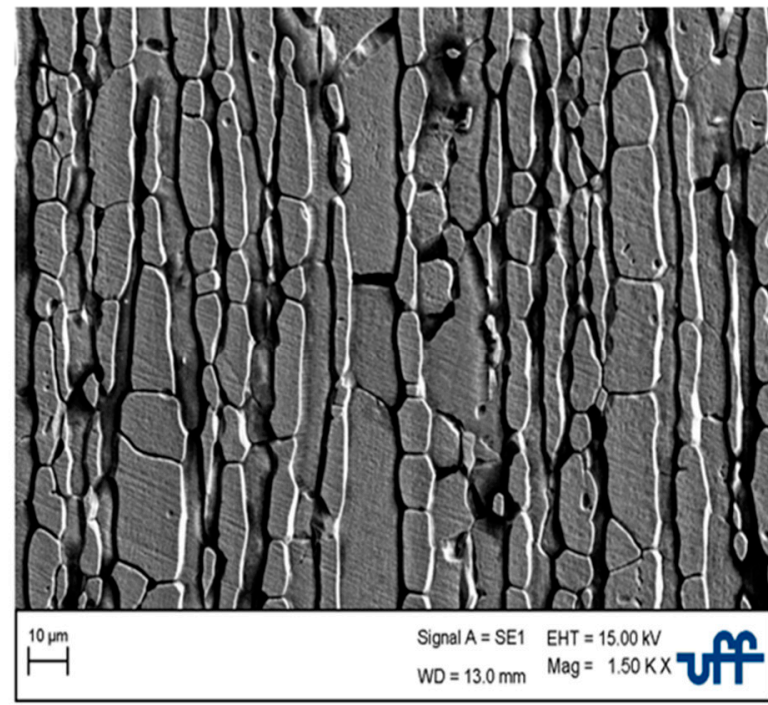

(a)

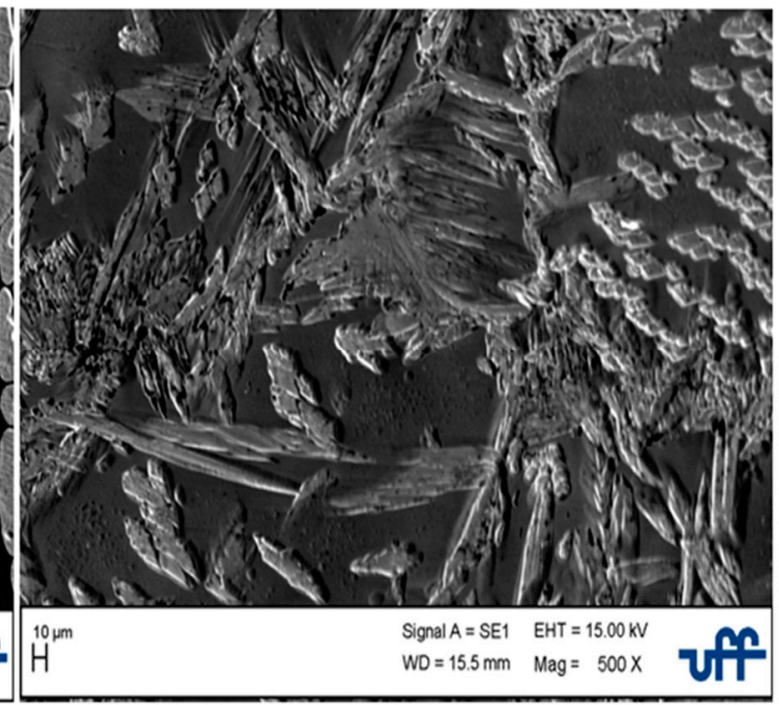

(b)

Figure 18. Microstructural aspects after electrochemical test. SAF 2507-High heat input. (a) Base metal, (b) Weld region.

After all the results presented, in relation to heat input-microstructure/quantification of ferrite, Heating/cooling rates distribution, Vickers hardness, Impact test, and electrochemical polarization-superduplex stainless steel 2507 meets all requirements and can be used by autogenous TIG. Thus, the welding parameters presented in this work with high heat input would be adequate for the SDSS 2507 because it maintains the ferrite-austenite balance, does not form deleterious phases that would weaken the steel, and it maintains with high corrosion resistance.

An honorable mention must be made about the behavior of SAF 2205 and SAF 2507 welded with medium heat input, since, with the exception of the amount of ferrite in WM (greater than $70 \%$ ), all other properties measured are within the standard.

\section{Conclusions}

The effect of different heat inputs in the autogenous TIG welding process on the microstructure, mechanical properties, and corrosion resistance for two DSS and one SDSS were analyzed, and the main conclusions were:

- In the HAZ and WM, besides the ferrite, there is austenite in three morphologies: allotriomorphic, intragranular, and Widmanstätten. The volumetric fraction of ferrite measured in each region (BM, LT-HAZ, HT-HAZ, WM) for each steel as a function of the heat input shows that SDSS 2507 welded with high input is within the values of the standard in all regions measures. An honorable mention must be made of the behavior of SAF 2205 and SAF 2507 welded with medium heat input, since, with the exception of the amount of ferrite in WM (greater than $70 \%$ ), all other regions are within the value stipulated by the standard. SAF 2304 presents values higher than $70 \%$ of ferrite in the HAZ and WM for all heat inputs used.

- The measured hardness value remained relatively constant and together with the micrographs shown and heating/cooling rates distribution simulation, shows that there is no precipitation of deleterious phases.

- The values obtained by Chapy impact test at $-46^{\circ} \mathrm{C}$ show that SAF 2205 and SDSS 2507 remained above the value of $27 \mathrm{~J}$ (acceptance limit). The higher absorbed energy obtained for samples welded with medium heat input compared to high heat input is related to the higher amount of 
AW formed in WM for high input, which would decrease the toughness. The energy absorbed by the SAF 2304 was below that required by the standard.

- SAF 2507 welded with high heat input has the highest corrosion potential value, indicating a higher corrosion resistance than the others.

- After all the results presented, the welding parameters presented in this work with high heat input would be adequate for SDSS 2507 because it maintains the ferrite-austenite balance, does not form deleterious phases that would weaken the steel, and it maintains with high corrosion resistance.

Acknowledgments: This work was supported by Fundação de Amparo a Pesquisado Estado do Rio de Janeiro, FAPERJ, Conselho Nacional de Desenvolvimento Cientıfico e Tecnológico, CNPq, and Coordenação de Aperfeiçoamento de Pessoal de Nível Superior, CAPES.

Author Contributions: Gláucio Soares da Fonseca and Carlos Roberto Xavier conceived and designed the experiments; Luis Otavio Rodrigues Barbosa performed the experiments; Elivelton Alves Ferreira and Luis Otavio Rodrigues Barbosa performed the electrochemical experiments; Luis Otavio Rodrigues Barbosa, Gláucio Soares da Fonseca, and Carlos Roberto Xavier analyzed the data; José Adilson de Castro ran the simulations; Gláucio Soares da Fonseca wrote the paper.

Conflicts of Interest: The authors declare no conflict of interest.

\section{References}

1. Fonseca, G.S.; Oliveira, P.M.; Diniz, M.G.; Bubnoff, D.M.; Castro, J.A. Sigma Phase in Superduplex Stainless Steel: Formation, Kinetics and Microstructural Path. Mater. Res. 2017, 20, 249-255. [CrossRef]

2. Escriba, D.M.; Materna-Morris, E.; Plaut, R.L.; Padilha, A.F. Chi-phase precipitation in a duplex stainless steel. Mater. Charact. 2009, 60, 1214-1219. [CrossRef]

3. Magnabosco, R. Kinetics of sigma phase formation in a Duplex Stainless Steel. Mater. Res. 2009, 12. [CrossRef]

4. Calliari, I.; Zanesco, M.; Ramous, E. Influence of isothermal aging on secondary phases precipitation and toughness of a duplex stainless steel SAF 2205. J. Mater. Sci. 2006, 41, 7643-7649. [CrossRef]

5. Karlsson, L. Welding duplex stainless steels-A review of current recommendations. Weld World 2012, 56, 65-76. [CrossRef]

6. Brytan, Z.; Niagaj, J. Corrosion resistance and mechanical properties of TIG and A-TIG welded joints of lean duplex stainless steel S82441/1.4662. Arch. Metall. Mater. 2016, 61, 771-784. [CrossRef]

7. Mohammed, G.R.; Ishak, E.; Aqida, S.N.; Abdulhadi, H.A. Effects of Heat Input on Microstructure, Corrosion and Mechanical Characteristics of Welded Austenitic and Duplex Stainless Steels: A Review. Metals 2017, 7, 39. [CrossRef]

8. Dobranszky, J.; Szabo, P.J.; Berecz, T.; Hrotko, V.; Portko, M. Energy dispersive spectroscopy and electron backscatter diffraction analysis of isothermally aged SAF 2507 type superduplex stainless steel. Spectrochim. Acta Part B 2004, 59, 1781-1788. [CrossRef]

9. Hsieh, C.C.; Wu, W. Overview of Intermetallic Sigma ( $\sigma)$ Phase Precipitation in Stainless Steels. ISRN Metall. 2012, 2012, 732471. [CrossRef]

10. Kobayashi, D.Y.; Wolynec, S. Evaluation of the low corrosion resistant phase formed during the sigma phase precipitation in duplex stainless steels. Mater. Res. 1999, 2, 239-247. [CrossRef]

11. Villanueva, D.M.E.; Junior, F.C.P.; Plaut, R.L.; Padilha, A.F. Comparative study on sigma phase precipitation of three types of stainless steels: Austenitic, superferritic and duplex. Mater. Sci. Technol. 2006, 22, 1098-1104. [CrossRef]

12. Elmer, J.W.; Palmer, T.A.; Specht, E.D. Direct Observations of Sigma Phase Formation in Duplex Stainless Steels Using In-Situ Synchrotron X-ray Diffraction. Metall. Mater. Trans. A 2007, 38, 464-475. [CrossRef]

13. Badji, R.; Bouabdallah, M.; Bacroix, B.; Kahloun, C.; Belkessa, B.; Maza, H. Phase transformation and mechanical behavior in annealed 2205 duplex stainless steel welds. Mater. Charact. 2008, 59, 447-453. [CrossRef]

14. Fan, K.; Liu, F.; Ma, Y.Z.; Yang, G.C.; Zhou, Y.H. Modeling of $\sigma$-phase precipitation in a 2205 duplex stainless steel using an analytical soft impingement treatment. Mater. Sci. Eng. A 2010, 527, 4450-4553. [CrossRef]

15. Xavier, C.R.; Delgado, J.H.G.; Castro, J.A. An experimental and numerical approach for the welding effects on the duplex stainless steel microstructure. Mater. Res. 2015, 18, 489-502. [CrossRef] 
16. Xavier, C.R.; Delgado, J.H.G.; Castro, J.A.; Ferreira, A.F. Numerical predictions for the thermal history, microstructure and hardness distributions at the HAZ during welding of low alloy steels. Mater. Res. 2016, 19, 520-533. [CrossRef]

17. Xavier, C.R.; Campos, M.F.; Castro, J.A. Numerical method applied to duplex stainless steel. Ironmak. Steelmak. 2013, 40, 420-429. [CrossRef]

18. Russ, J.C.; Dehoff, R.T. Practical Stereology, 2nd ed.; Kluwer Academic/Plenum Publishers: New York, NY, USA, 2000; pp. 45-78, ISBN 0-306-46476-4.

19. ASTM Standard E23-16b. Standard Test Methods for Notched Bar Impact Testing of Metallic Materials; ASTM International: West Conshohocken, PA, USA, 2016. [CrossRef]

20. Norsok Standard M-601. Welding and Inspection of Piping; Standards Norway: Lysaker, Norway, 2008.

21. Deng, B.; Jiang, Y.; Gong, J.; Zhong, C.; Gao, J.; Li, J. Critical pitting and repassivation temperatures for duplex stainless steel in chloride solutions. Electrochim. Acta 2008, 53, 5220-5225. [CrossRef]

22. IMOA International Molybdenum Association. Available online: http://www.imoa.info/download_files/ stainless-steel/Duplex-Stainless-Steel_3rd_Edition.pdf (accessed on 10 January 2017).

23. Porter, D.A.; Easterling, K.E. Phase Transformations in Metals and Alloys, 2nd ed.; Chapman \& Hall: London, UK, 1992; pp. 185-260, ISBN 0-412-45030-5.

24. Sieurin, H.; Sandström, R. Sigma phase precipitation in duplex stainless steel 2205. Mater. Sci. Eng. A 2007, 444, 271-276. [CrossRef]

25. Callister, W.D., Jr. Materials Science and Engineering: An Introduction, 7th ed.; John Wiley \& Sons: New York, NY, USA, 2007; pp. 207-251, ISBN 978-0-471-73696-7.

26. Muthupandi, V.; Srinivasan, P.B.; Seshadri, S.K.; Sundaresan, S. Chi Effect of weld metal chemistry and heat input on the structure and properties of duplex stainless steel welds. Mater. Sci. Eng. A 2003, 358, 9-16. [CrossRef]

(C) 2017 by the authors. Licensee MDPI, Basel, Switzerland. This article is an open access article distributed under the terms and conditions of the Creative Commons Attribution (CC BY) license (http://creativecommons.org/licenses/by/4.0/). 